Research Paper

\title{
MicroRNA-196a promotes renal cancer cell migration and invasion by targeting BRAM1 to regulate SMAD and MAPK signaling pathways
}

\author{
Jianzhou Cui1,2,3\#, Yi Yuan",2,4,5\#, Muthu K. Shanmugam6, Durkeshwari Anbalagan1,2, Tuan Zea Tan,5, \\ Gautam Sethi', Alan Prem Kumar ${ }^{4,5,6,7 凶}$, Lina H. K. Lim¹,2, ${ }^{\circledR}$
}

1. Department of Physiology , Yong Loo Lin School of Medicine, National University of Singapore, Singapore 117456, Singapore.

2. NUS Immunology Programme, Life Sciences Institute, National University of Singapore, Singapore 117456, Singapore.

3. Immunology Translational Research Program, Yong Loo Lin School of Medicine, National University of Singapore, Singapore 117597, Singapore.

4. NUS Centre for Cancer Research, Yong Loo Lin School of Medicine, National University of Singapore, Singapore 117599, Singapore.

5. Cancer Science Institute of Singapore, Yong Loo Lin School of Medicine, National University of Singapore, Singapore 117559, Singapore.

6. Department of Pharmacology, Yong Loo Lin School of Medicine, National University of Singapore, Singapore 117559, Singapore.

7. National University Cancer Institute, Singapore 119074, Singapore.

\#These authors contributed equally to this manuscript.

$\square$ Corresponding authors: Dr. Lina Hsiu Kim Lim, Department of Physiology, NUS Immunology Programme, Yong Loo Lin School of Medicine, 28 Medical Drive, Centre for Life Sciences Immunology Program Level 3, National University of Singapore, Singapore 117597. Phone: +65-6516 5515; Fax: +65-6516 7582; E-mail: linalim@nus.edu.sg; Dr. Alan Prem Kumar, Cancer Science Institute of Singapore, Center for Translational Medicine, 14 Medical Drive, National University of Singapore, Singapore 117599. Phone: + 65-65165456; Fax: +65-68739664; E-mail: apkumar@nus.edu.sg.

(c) The author(s). This is an open access article distributed under the terms of the Creative Commons Attribution License (https://creativecommons.org/licenses/by/4.0/). See http://ivyspring.com/terms for full terms and conditions.

Received: 2021.03.26; Accepted: 2021.09.16; Published: 2021.10.17

\begin{abstract}
Rationale: MicroRNAs (miRNAs) are endogenous $\sim 22 \mathrm{nt}$ RNAs that play critical regulatory roles in various biological and pathological processes, including various cancers. Their function in renal cancer has not been fully elucidated. It has been reported that miR-196a can act as oncogenes or as tumor suppressors depending on their target genes. However, the molecular target for miR-196a and the underlying mechanism in miR-196a promoted cell migration and invasion in renal cancer is still not clear.

Methods: The expression, survival and correlation between miR-196a and BRAMI were investigated using TCGA analysis and validated by RT-PCR and western blot. To visualize the effect of Bram l on tumor metastasis in vivo, NOD-SCID gamma (NSG) mice were intravenously injected with RCC4 cells (106 cells/mouse) or RCC4 overexpressing Braml. In addition, cell proliferation assays, migration and invasion assays were performed to examine the role of miR-196a in renal cells in vitro. Furthermore, immunoprecipitation was done to explore the binding targets of Braml.

Results: TCGA gene expression data from renal clear cell carcinoma patients showed a lower level of Braml expression in patients' specimens compared to adjacent normal tissues. Moreover, Kaplan-Meier survival data clearly show that high expression of Bram l correlates to poor prognosis in renal carcinoma patients. Our mouse metastasis model confirmed that Braml overexpression resulted in an inhibition in tumor metastasis. Target-prediction analysis and dual-luciferase reporter assay demonstrated that Bram 1 is a direct target of miR-196a in renal cells. Further, our in vitro functional assays revealed that miR-196a promotes renal cell proliferation, migration, and invasion. Rescue of Braml expression reversed miR-196a-induced cell migration. MiR-196a promotes renal cancer cell migration by directly targeting Bram 1 and inhibits Smad1/5/8 phosphorylation and MAPK pathways through BMPRIA and EGFR.

Conclusions: Our findings thus provide a new mechanism on the oncogenic role of miR-196a and the tumor-suppressive role of Braml in renal cancer cells. Dysregulated miR-196a and Braml represent potential prognostic biomarkers and may have therapeutic applications in renal cancer.
\end{abstract}

Key words: MicroRNA-196a; renal cancer; Bram1; migration and invasion; SMAD and MAPK pathways 


\section{Introduction}

MicroRNAs (miRNAs) are endogenous $\sim 22 \mathrm{nt}$ RNAs that can play important regulatory roles in animals and plants. They can bind to their target mRNAs by complete or partial complementarily of their 5 '-end nucleotides 2-8 (seed sequences) with a binding site in the $3^{\prime}$-UTRs of their target transcripts, which subsequently results in either direct cleavage of the targeted mRNAs by nucleases within the RISC or inhibition of their translation [1]. Since their discovery in 1993 in C. elegans, these tiny oligonucleotides have been shown to play critical regulatory roles in a wide range of biological and pathological processes including cancer [2]. Since 2002, an increasing number of miRNAs have been aberrantly expressed in various cancer cell lines and clinical tumor specimens. In general, miRNAs that are overexpressed in cancer are thought to act as oncogenic miRNAs by suppressing tumor suppressor, pro-apoptotic and growthinhibitory genes. Down-regulated or absent miRNAs may present themselves as tumor suppressive as they usually repress oncogenes and proliferation-related genes [3]. The identification of putative mRNA targets is important to understand the specific functions of miRNAs.

Renal cell carcinoma (RCC) represents the most common kidney malignancy and 3\% of total human cancers. According to the WHO classification of renal cancer, there are five subtypes: clear cell, multilocular cystic, papillary, chromophobe, and collecting duct carcinomas [4]. Research on miRNAs in renal cancer is less studied as compared to other cancers. The deregulation of miRNA has been found in all the subtypes of renal cancer cells [5], and the difference between specific miRNAs expression can be used to profile the five subtypes or as potential biomarkers in different stages of renal cancer carcinoma [6]. In addition, by using the microarrays and RT-PCR, miRNA expression in a group of patients who developed metastasis compared with those who have non-metastatic tumors or primary RCCs was altered, such as miR-106b, miR-451, miR-221, miR-155 [7-10]. This suggests that the selected miRNAs might be potential biomarkers for metastasis of RCCs, but further studies and validations are needed.

MicroRNA-196a appears to play an important role in development and cancer. The up-regulation of miR-196a has been found in many cancers such as pancreatic cancer [11], breast cancer [12], esophageal adenocarcinoma [13], colorectal cancer [14], non-small cell lung carcinoma [15], gastric cancer [16] and intraductal papillary mucinous neoplasm [17]. Although most studies on miR-196a suggest its oncogenic function in cancer, miR-196a may play a tumor suppressive role as well. For example, a strongly reduced expression of miR-196a was observed in melanoma cells compared to healthy control melanocytes [18], which may suggest that the functional role of miR-196a in cancer may be tissueand cell type-specific. The mechanisms of action of miR-196a in different cancer types are largely unknown. It may depend on the molecules which miR-196a targets. It has been reported that miR-196a can directly target HOXA5 [15], HOXA9 [19], p27kip1 [20], ANXA1 [21], ERG [22], NOBOX [23], FOXO1 [24], Netrin 4 [25], RAP1A [26], IkBa [27], radixin [28], and NFKBIA [29], or downregulation of HOXA7, HOXB8, HOXC8, HOXD8 [14], HOXB7 [18], CELF2 [30] and NME4 [31] and have several functions in different cancers. Also, miR-196a plays a functional role by regulating gene expression such as HOX-C8 [32], HOX-B7, BMP4 [18] and RAP1A [26]. Liu et al. [15] demonstrated that miR-196a could promote cell invasion via targeting HOXA5, while Luthra et al. [21] suggested that the ectopic expression of miR-196a is associated with decreased cell migration. The effect of miR-196a is rescued by over-expressing ANXA1, which may also suggest that the functional role of miR-196a in cancer may be tissue- and cell typespecific. Thus, the function and targets of miR-196a in renal cancer cells remain unknown.

Bram1 (bone morphogenesis protein receptor associated molecule 1) is an alternatively spliced gene of BS69, which has been identified as a transcription suppressor gene [33]. The $C$ terminal of Bram1 is binds to BMP1A and may serve as an interacting protein in the BMP signal pathway [33], which is also confirmed in zebrafish [34]. BRA-1, one homolog of Bram1 in Caenorhabditis elegans, binds to DAF-1 and negatively regulates transforming growth factor-beta (TGF- $\beta$ ) and DAF7 pathways [35]. Besides, the MYND domain of Bram1 can also interact with the CTAR2 region of Epstein-Barr virus-encoded LMP1 (latent membrane protein 1), which acts as a constitutively activated tumor necrosis factor receptor (TNFR), therefore negatively regulates LMP1-mediated NFKB activation but not JNK activity [36]. Bram1 was shown to be associated with the lymphotoxin beta receptor (LT $\beta R$ ), a TNFR-superfamily member. Bram1 reacts with LT $\beta R$ mainly through the self-association domain of LT $\beta R$ (aa 336-398), constitutively abrogates its function [37].

As mentioned above, miR-196a and Bram1 both showed an essential role in renal cancer cells. However, the correlation and underlying mechanisms between them remain unclear. Here, we performed a systematic, integrated analysis and investigated the role and target of miR-196a in renal cancer cells, namely BRAM1 and unveiled the mechanisms on how it plays a role as a tumor suppressor gene in 
renal cancer metastasis. Our results suggest that regulation of the renal miR-196a and Bram1 levels may be a novel therapeutic strategy for treating RCC.

\section{Materials and Methods}

\section{Clinical database}

The Bram1 gene expression in FPKM values of TCGA renal clear cell carcinoma (KIRC; $\mathrm{N}=534$ ) available on Broad GDA, data version 2016_01_28 was extracted for analysis (https://gdac.broadinstitute. org/). The hsa-miR-196a expression in counts per million read were extracted from the KIPC and KIRP mi-RNA-seq.

\section{Cell culture}

Human cell line HEK293, HEK293T, 786-O and Caki1 were obtained from American Type Culture Collection (ATCC, Manassas, VA, USA), RCC4 cell line was kindly provided by Dr. John Yuen, Department of Urology, Singapore General Hospital. Human embryonic cell line HEK293 (used for gene expression level examination), HEK293T (used for transfection experiments), human renal cancer cell lines RCC4 and 786-O were grown as monolayers in Dulbecco's Modified Eagle's Medium (DMEM, Serana, Australia) supplemented with 10\% heatinactivated fetal bovine serum (FBS, Biowest LLC, Kansas, MO, USA), 1\% penicillin-streptomycin (GE Healthcare Life Sciences, HyClone Laboratories, Utah, USA). Human renal cancer cell line, Caki1 was cultured in RPMI (Serana, Australia) with 10\% heat-inactivated FBS, $1 \%$ penicillin-streptomycin. All cell lines were kept at $37^{\circ} \mathrm{C}$ in a humid atmosphere containing 5\% CO2 (Thermo Fisher Scientific Inc, MA, USA).

\section{Cell transfection}

The miR-196a sequences were amplified and cloned into pSilencer 4.1 CMV neo, and the wild type 3'UTR-Bram1 was cloned in to pSiCheck 2 vectors, pSiCheck-3'UTR-Bram1-mut were cloned by using the mutagenesis kit. According to the manufacturer's instruction, transfection (using Turbofect transfection reagent (Fermentas, USA) of the plasmids was performed in the various cell lines. pCMV-Bram 1 and psupe-shBram1 and the negative controls are kind gifts from Dr. Yu-San Chang in Chang-Gung University. The sequences of all the plasmids were sent for sequencing in 1st Base company (Singapore) to ensure the constructs were correct. For plasmids transfection, empty GFP (500 ng) was co-transfected together with $1 \mu \mathrm{g}$ of plasmids DNA in 12-well plates to assess transfection efficiency. After 24 hours, the cells were viewed using a fluorescent microscope at 10X magnification. At 36-48 hours after transfection, cells were harvested for Western blotting or RT-PCR analyses or other experiments.

For anti-miR transfection, human miRNA inhibitor negative control (5 nmol, mG/ZEN/ mCmGmUmAmUmUmAmUmAmGmCmCmGmAm UmUmAmAmCmG/3ZEN/) and anti-hsa-196a (5 nmol, $\mathrm{mC} / \mathrm{ZEN} / \mathrm{mCmCmAmAmCmAmAmCmAm}$ UmGmAmAmAmCmUmAmCmCmU/3ZEN/) were synthesized in Integrated DNA Technologies (IDT, Singapore). RCC4 cells were transfected with hsa-196a anti-miR inhibitor $(50 \mathrm{nM})$ and inhibitor negative control $(50 \quad \mathrm{nM})$ using $2 \mu \mathrm{L}$ Lipofectamine ${ }^{\mathrm{TM}}$ RNAiMAX Transfection Reagent (Cat\# 13778075) in 12-well plates.

\section{RNA extraction and RT-PCR}

Total RNA was isolated with TRIzol reagent (Invitrogen, USA) according to the manufacture's protocol. miRNA was extracted using the NcleoSpin miRNA kit from Macherey-Nagel (Germany) according to the manufacture's protocol. Quantitative and qualitative RNA analyses were performed using NanoDrop 1000 spectrophotometer (Thermo Scientific). For samples to check gene levels, RNA was reverse transcribed to cDNA by using a Reverse Transctiption Kit (Promega). Real-time PCR (RT-PCR) analysis was conducted with GoTaq ${ }^{\circledR}$ qPCR master mix (Promega). For samples for microRNA study, cDNA synthesis and RT-PCR with the miRCURY LNATM system were conducted according to the manufacturer's protocol. Results were normalized to the expression of glyceraldehyde-3-phosphate dehydrogenase (GAPDH) or U6. RT-PCR and data collection were carried out on ABI7500.

\section{Western Blot assay}

Cells were washed with cold PBS and lysed in mammalian protein extraction reagent RIPA buffer supplemented with protease and phosphatase inhibitors cocktail (Roche). Proteins were quantified by 1X Bradford's reagent (BioRad Protein Assay). Fifty microgram of total protein per samples were separated by $10 \%$ SDS polyacrylamide gel electrophoresis and transferred to a nitrocellulose membrane (BioRad). Proteins present in the membrane were incubated with specific antibodies and developed with a Konica Minolta SRX-101A tabletop processor. The antibodies used in our experiments included: Anti-Rabbit Bram1( Cell Signaling Technology (CST), Inc Danvers, MA, U.S.A); Anti-Rabbit BMPR1A (Gene tex Inc, San Antonio, Texas, U.S.A); Anti-Rabbit p-ERK (CST, Danvers, MA, U.S.A); Anti-Rabbit totalERK (CST, Danvers, MA, U.S.A); Anti-Rabbit p-p38 (CST, Danvers, MA, U.S.A); Anti-Rabbit total-p38 (CST, Danvers, MA, U.S.A); Anti-Rabbit p-JNK (CST, 
Danvers, MA, U.S.A); Anti-Rabbit total-JNK (CST, Danvers, MA, U.S.A); Anti-Rabbit p-SMAD1/5 (CST, Danvers, MA, U.S.A); Anti-Rabbit EGFR (CST, Danvers, MA, U.S.A); Anti-Mouse Tubulin (SigmaAldrich Co St. Louis, MO, U.S.A.).

\section{Cell proliferation assays}

5000 cells transfected with miR-196a or antimiR-196a or negative controls cells were harvested and plated in 96-well plates containing normal media until visibly confluent (80\%). Cell proliferation as well as cell counting assays were determined using CellTiter 96® (aqueous one solution cell proliferation) assay kit according to the manufacturer's instruction (Promega). Plates were incubated at $37^{\circ} \mathrm{C}$ for $2 \mathrm{hr}$ before reading OD at $490 \mathrm{~nm}$.

For the colony-forming assay, 1000 cells transfected with miR-196a or anti-miR-196a or negative controls cells were harvested and plated in 6-well plates, after one week the cells were stained with $0.5 \%$ crystal violet (Amersco) and the pictures were captured using ChemiDoc ${ }^{\mathrm{TM}}$ Touch Imaging System (Bio-Rad). Cell Colonies were counted by using OpenCFU, an open-Source Software [38].

\section{Cell migration and invasion assay}

Wound healing assay and transwell assay are used for detecting cell migration and invasion. For wound healing assay, $1 \times 10^{6}$ cells were seeded in 6-well plates overnight and transfected with relative plasmids. Streaks were created in the monolayer with a pipette tip at $6 \mathrm{hr}$ post transfection. Progression of wound closure was observed and photographed at 0 $\mathrm{hr}, 24 \mathrm{hr}$ after wounding. For transwell assay, $24 \mathrm{hr}$ after transfection with relative plasmids, $2.5 \times 10^{5}$ cells in serum free medium were placed into the Matrigel transwell chambers consisting of polycarbonate membranes (8- $\mu \mathrm{m}$ pore size, millipore). Medium containing $10 \%$ FBS was added to the lower chambers. Following incubation for $48 \mathrm{hr}$, cells that remained on the top of the filter were removed and cells that migrated to the lower surface were counting.

\section{MiRNA target gene prediction}

Correlation between miR-196a and gene expression data of predicted targets using Target Scan, miRWalk, DIANAmicroT and PicTar [39] were performed to find potential miR-196a target genes. The miR-196a mature sequences of human were obtained from the miRBase database.

\section{Dual luciferase reporter assay}

Cells with $80 \%$ confluency were transfected with $100 \mathrm{ng}$ of wide type or mutant plasmids in serum-free DMEM medium with and without miRNAs. After 24 $\mathrm{hr}$, luciferase activity was determined using Dual-
Luciferase ${ }^{\circledR}$ Reporter Assay System (Promega) according to the manufacturer's protocol. Cells were lysed in $120 \mu$ of $1 X$ lysis buffer, centrifuged at 10000 $\mathrm{g}$ for 10 minute and supernatants were collected. The results were expression as relative promoter luciferase activity compared to controls after normalizing for Renilla activity. Luminescence was measured using a spectrophotometer (Perkin Elmer VICTOR3 ${ }^{\mathrm{TM}} \mathrm{V}$ Multilabel Counter Model 1420).

\section{Immunoprecipitation}

Cells were harvested in Immunoprecipitation (IP) lysis buffer and centrifuged at $4{ }^{\circ} \mathrm{C}$. Concentration was quantified by BioRad Protein Assay and $500 \mu \mathrm{g}$ of lysates were used for each reaction. Beads $(20 \mu \mathrm{l})$ were washed and added to each lysate for pre-clearing, and $50 \mu \mathrm{l}$ of beads were incubated with control IgG or specific antibody for 4 hour antibody-coupled beads. The pre-cleared lysates were mixed with antibodycoupled beads and incubated overnight. The next day, after washing the beads, $4 \mathrm{X}$ loading buffer was added to beads and heated at $95^{\circ} \mathrm{C}$ for $10 \mathrm{~min}$. Western Blot assay was followed to quantify the protein in the samples.

\section{In vivo metastasis model}

All the procedures involving animals were reviewed and approved by National University of Singapore Institutional Animal Care and Use Committee (Protocol number R17-0975) and National Advisory Committee for Laboratory Animals Research (NACLAR). To test the effect of Bram1 on tumor metastasis, female NOD-SCID gamma (NSG) mice (In vivos, Singapore) were injected with RCC4 cells ( $10^{6}$ cells/mouse) with stable empty vector or overexpression of Bram1 expression via tail vein (ten mice per group). After 4 weeks, mice were sacrificed; lung and liver metastatic nodules were detected in paraffin-embedded sections stained with hematoxylin and eosin following standard staining procedure. Images were taken using Leica DM6 microscope (magnification, 10x, 20x and 40x) and the images were captured using the Leica THUNDER imager.

\section{Statistical Analysis}

Student's t-test (two-tailed) and One-way ANOVA were performed to analyze the data, $p$ values less than 0.05 were considered statistically significant.

\section{Results}

\section{Expression of BRAMI in Kidney Renal Clear Cell Carcinoma (KIRC) TCGA cohort}

We first determined the overall expression level changes in Bram1 (also known as ZMYND11) in all 
cancers using https:/ / tnmplot.com/analysis/, which uses 56,938 unique multilevel quality controlled samples. (Figure 1A) [40]. Similar to many other cancers, expression of BRAM1 was significantly reduced in renal clear cell carcinoma (light blue, CC) and papillary carcinoma (blue, PA). To confirm this, gene expression (FPKM) data from the TCGA renal clear cell carcinoma (KIRC) cohort was next downloaded from Broad GDAC Firehose (broadinstitute.org). The updated clinical outcome of TCGA cohorts were obtained from TCGA Pan-Cancer
Clinical Data Resource. As shown in Figure 1B and C, lower Bram1 expression was detected in tumor samples and renal clear cell cancer samples compared with adjacent normal tissues and papillary clinical samples respectively. Kaplan-Meier survival analyses demonstrated that the expression of Bram1 was positively associated with the survival of patients with KIRC (Figure 1D). In addition, a lower level of Bram1 expression was detected in lymph node metastasis samples (N1, Figure 1E).

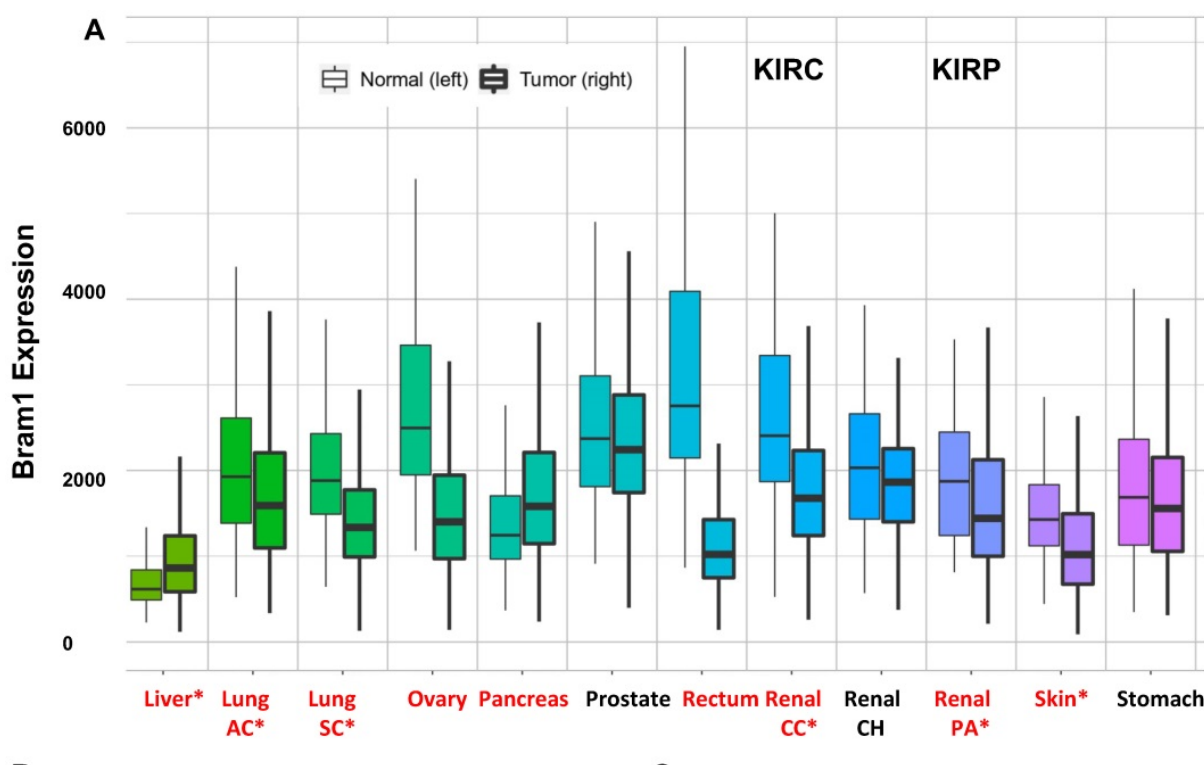

B

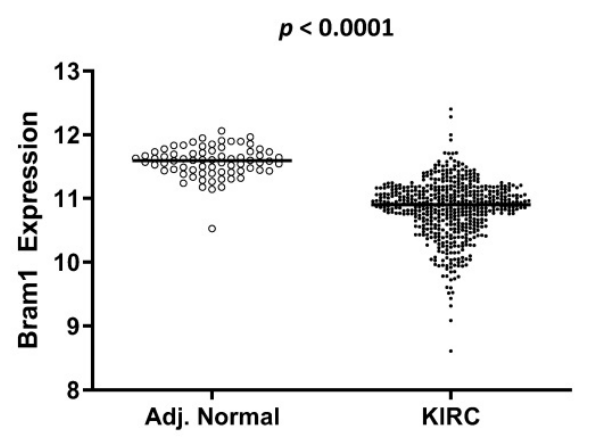

D

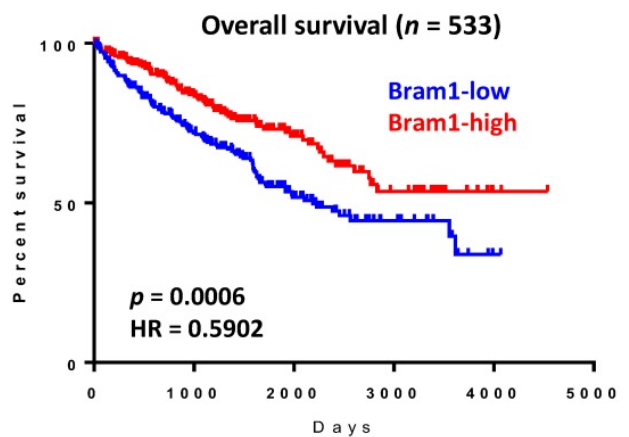

C
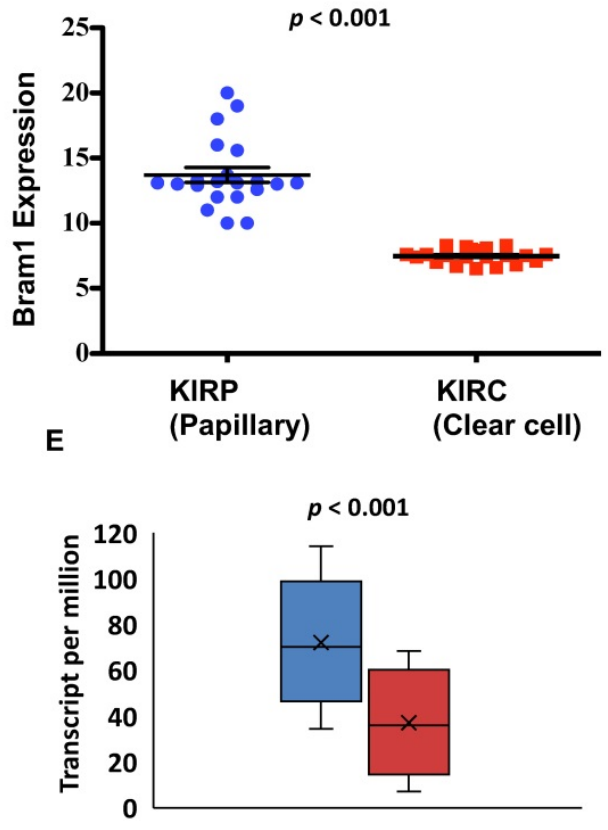

$\square$ Normal (n=72) $\square$ N1 (n=16)

Figure 1. Expression pattern of Bram 1 in clinical samples. (A) The gene expression pattern analysis of Braml in normal tissues and tumors based on TCGA data and (B) for KIRC. (C) Expression of Braml in clear cell renal cancer samples compared to papillary clinical samples. $p<0.001$. (D) Kaplan-Meier survival curves analysis for patients in TCGA renal clear cell carcinoma (KIRC) cohort (Red $=$ high, blue $=$ low; $p=0.0006$ ). (E) Expression of Braml in KIRC based on nodal metastasis status. Pathologic descriptions of $\mathrm{NI}$ : Metastases in 1 to 3 axillary lymph nodes. 
A

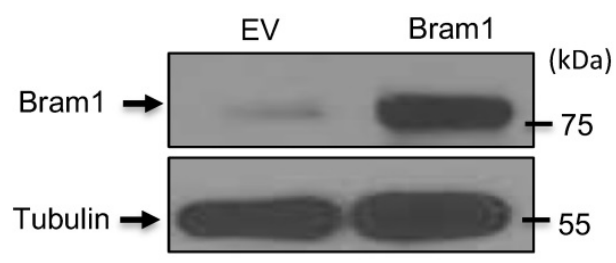

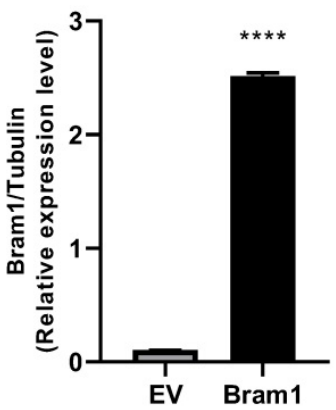

D
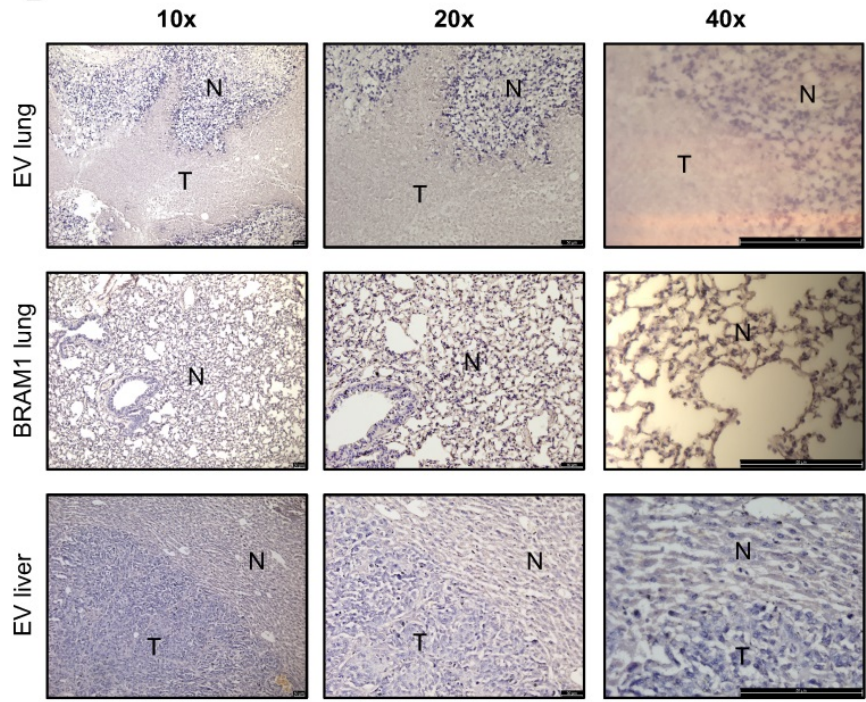

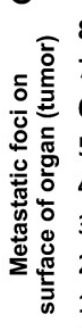
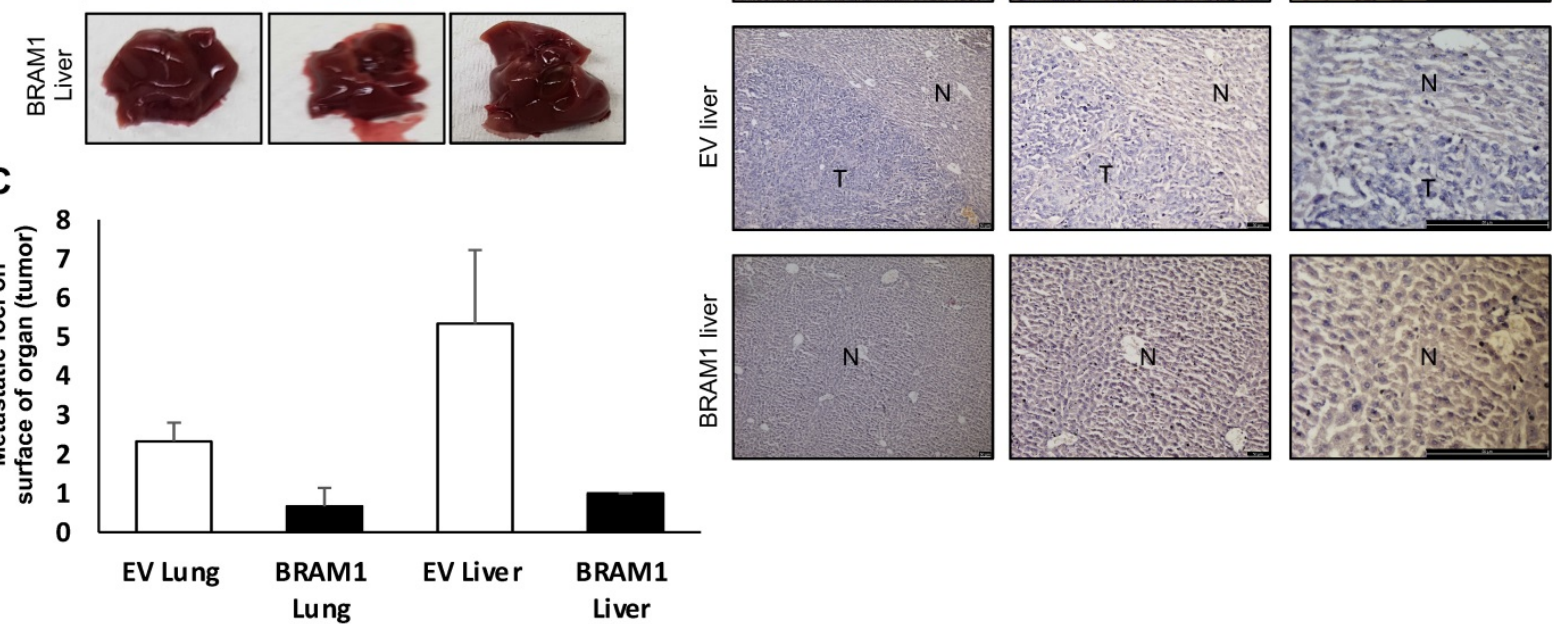

Figure 2. Bram 1 overexpression inhibits metastasis in mice. (A) BRAM 1 expression in RCC4 cells stably transfected with empty vector or Bram 1 overexpressing plasmids. (B) Representative images of metastatic lungs and livers of mice injected with Braml overexpression vector or empty vector (EV). (C) Quantification of the metastatic foci of the lung and liver of mice injected with Braml overexpression vector or empty vector (EV). (D) Representative images of hematoxylin and eosin staining of metastatic lung and liver samples collected from the control and Braml overexpressed groups ( $\mathrm{N}=\mathrm{Normal}, \mathrm{T}=\mathrm{Tumor}$ ).

\section{Overexpression of Bram 1 inhibits metastasis in mice}

Next, we investigated whether overexpression of Bram1 expression could affect tumor metastasis in a xenograft metastasis model in which RCC4 cells were used to generate pulmonary and liver metastases. Stably transfected RCC4 cells were generated either with empty vector (EV) or Bram1 over-expression (OE). Overexpression level of Bram1 is confirmed via western blot as shown in Figure 2A. Strikingly, overexpression of Bram1 greatly suppressed lung and liver metastasis in vivo. The quantification of the metastatic foci indicated that Bram1-OE mice developed fewer metastatic foci on the lung and liver surface than EV mice (Figure 2B, C). These observations were further confirmed by performing H\&E staining (Figure 2D), which showed that the density of the lung and liver metastases in Bram1-OE cells was higher than that of the EV tissue samples. These data collectively suggested that high expression of Bram1 may prevent metastasis of renal cancer cells in vivo.

\section{The negative correlation between miR-196a and Bram 1 in renal cancer cells}

MiR-196a has been shown to be down-regulated in metastatic renal cancer cells [9], yet the expression 
of miR-196a in primary renal cancer is not reported. Therefore, we investigated the expression of miR-196a in the database of renal cancer samples (Figure 3A). Compared to the papillary group, miR-196a is significantly overexpressed in clear cell renal cancer cells. Further, a negative correlation between the miR-196a and Bram1 in renal tumors (Figure 3B), suggests that miR-196a and Bram1 play an inverse function in renal cancer cells. This can also be seen with BRAM1 expression in clinical samples, where Bram1 is expressed at lower levels (Figure 1). In cell lines, miR-196a was over-expressed in all the three renal cancer cell lines compared to HEK293 cells (Figure 3C). Based on the expression level of miR-196a in different renal cancer cells, miR-196a plasmids were overexpressed in HEK293T cells while anti-miR-196a were transfected in RCC4 cells for the subsequent experiments. We next determined the expression of Bram1 in RCC4, 786-O and Caki1 renal cancer cells. As expected, Bram1 was expressed lower in all the three renal cancer cells, compared to HEK293 cells (Figure 3D), while miR196a is expressed at a higher level. Thus, a negative correlation of miR196a and Bram1 expression, can be observed indicating that Bram1 might be a potential target for miR-196a.

A

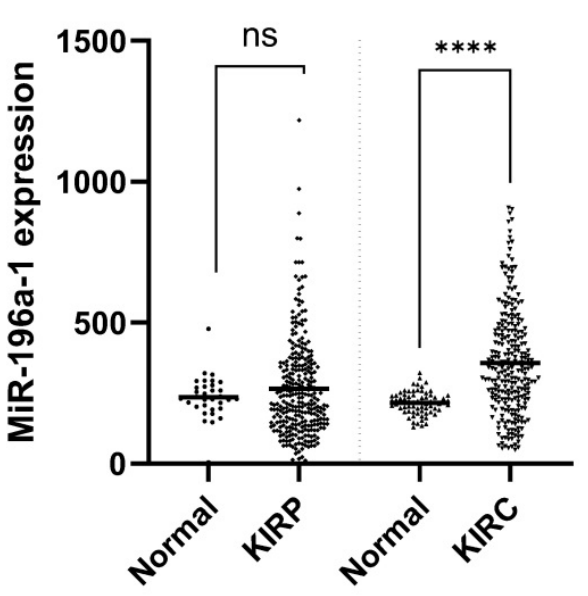

C

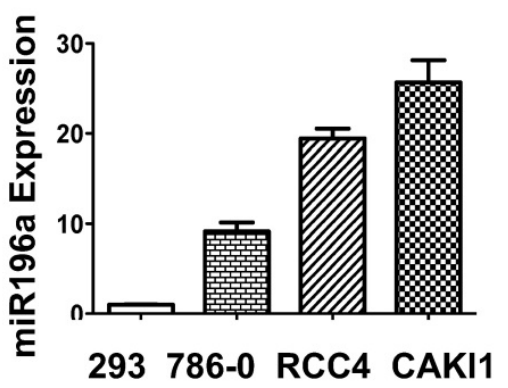

MiR-196a promotes embryonic renal cell proliferation, migration and invasion in vitro

Cell titer assay and cell counting assay were conducted to detect the effects of miR-196a on renal cell proliferation (Figure 4A). MiR-196a transfection into HEK293T significantly increased cell proliferation when compared to the control group in both assays. In contrast, RCC4 cells transiently transfected with anti-miR-196a nucleotides exhibited significantly lower cell proliferation compared to the cells transfected with anti-miR-control nucleotides. Furthermore, colony-formation capacity increased significantly after HEK293T cells were transfected with miR-196a. In contrast, when RCC4 cells transfected with anti-miR-196a nucleotides, the colony-formation capacity decreased significantly compared with untransfected cells and control cells (Figure 4B).

Next, the effect of miR-196a on renal cell migration and invasion was investigated via wound healing assay and trans-well assays. MiR-196a significantly enhances renal cell migration and invasion, while anti-miR-196a inhibits renal cancer cell migration (Figure 4C) and invasion (Figure 4D). Hence, we conclude that miR-196a promotes renal cell proliferation, migration, and invasion in vitro.
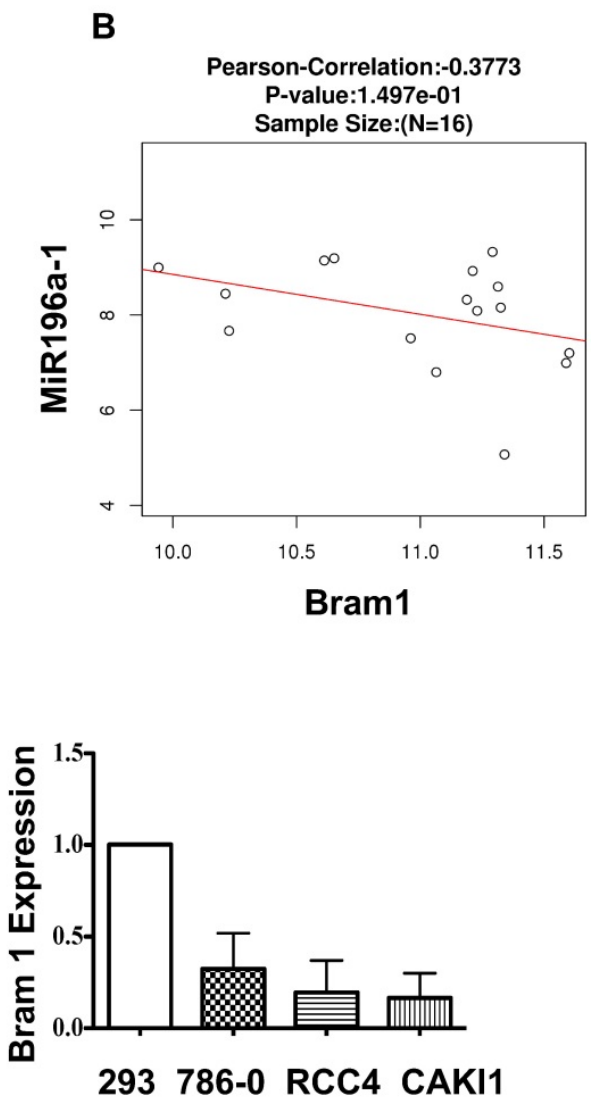

Figure 3. Negative correlation between the miR-196a and Braml. (A) MiR-196a overexpression in clear cell renal cancer samples and papillary clinical samples. $p=$ 1.69E-7. (B) The negative correlation between miR-196a and Braml expression in clinical samples. (C, D) The expression level of miR-196a and Braml was quantified by RT-PCR in renal cells. 


\section{Bram 1 is a direct target of miR-196a in renal cells}

Potential molecular targets for miR-196a were chosen using the microRNA target prediction software (Target Scan, miRWalk, DIANAmicroT and PicTar). Aside from those which have been reported, the top 8 candidates are listed according to their binding scores to miR-196a (Table 1). Bram1 was shown to have the highest binding score to miR-196a among all these 8 candidates. To further investigate whether these targets are transcriptionally regulated by miR-196a, the expression of these candidate targets in miR-196a overexpressed HEK293T cells was quantified by RT-PCR (Figure 5A). Among all the 8 targets, only Bram1 was significantly inhibited with miR-196a transfection. This result confirmed the prediction analysis and suggests that Bram1 may be a candidate target for miR-196a in renal cancer cells.
A
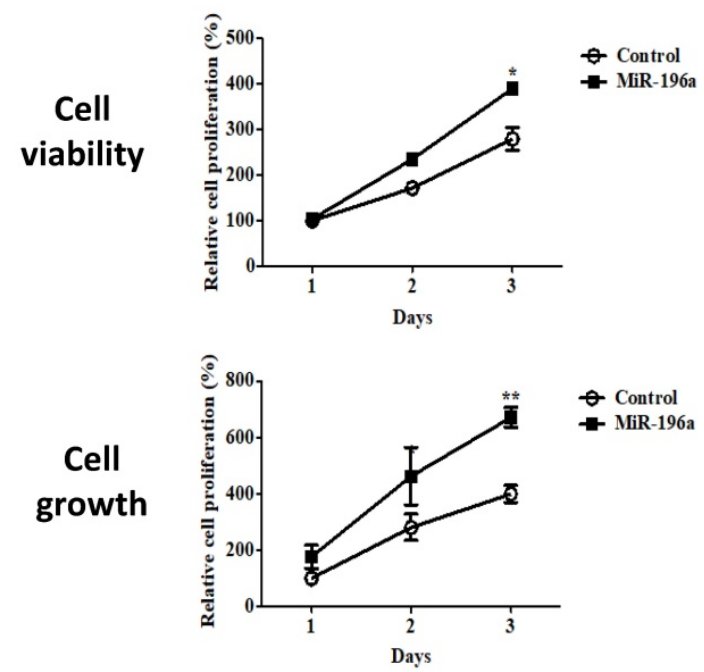

B
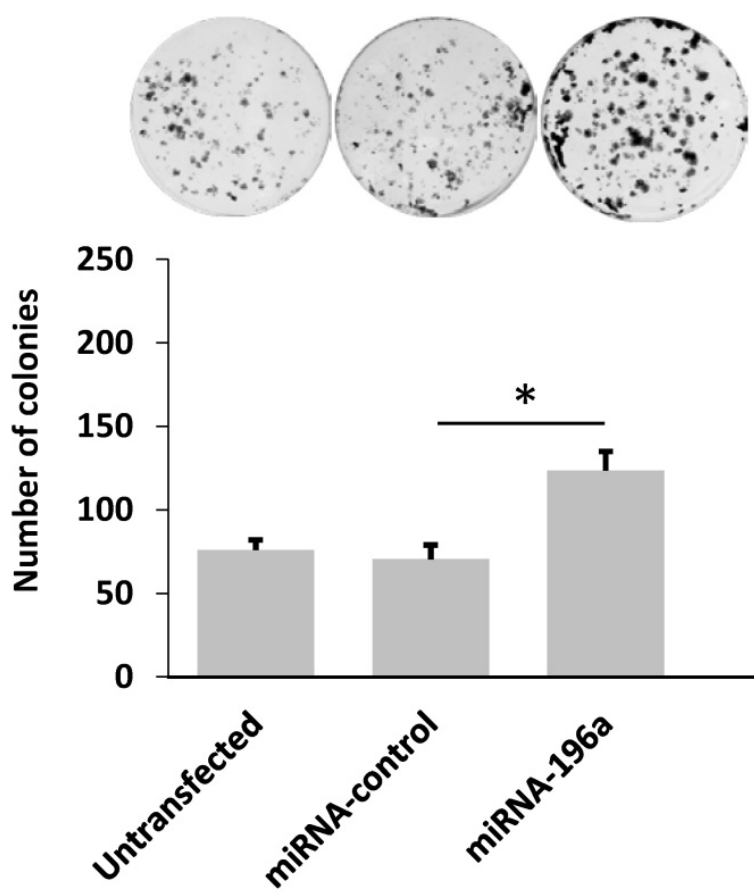
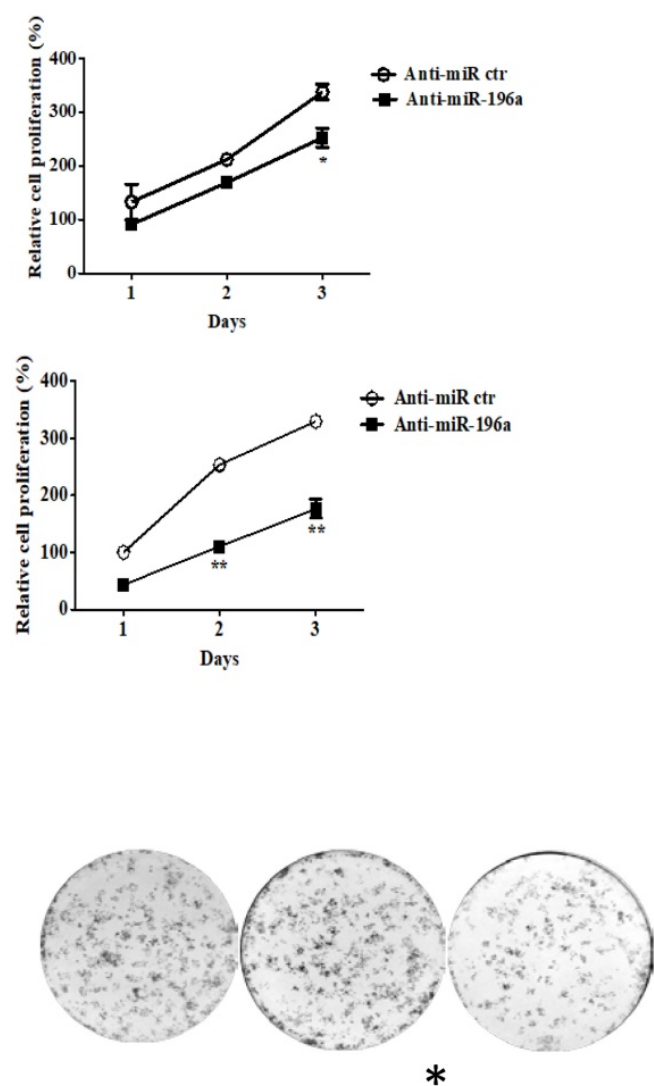

$*$
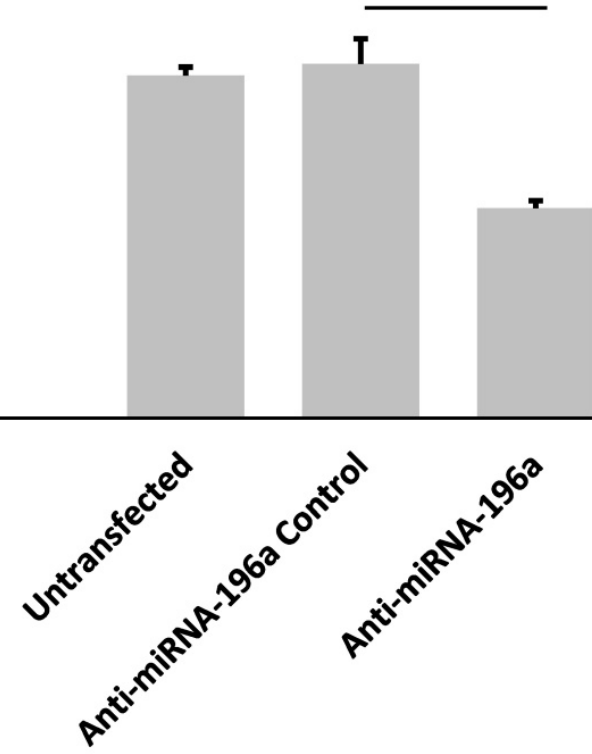

RCC4

HEK293T 
C
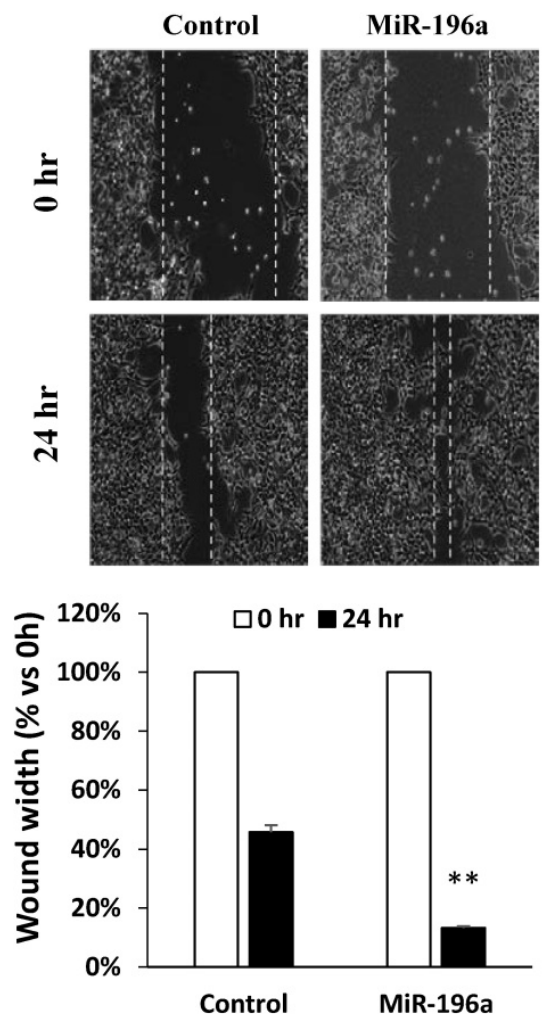

D

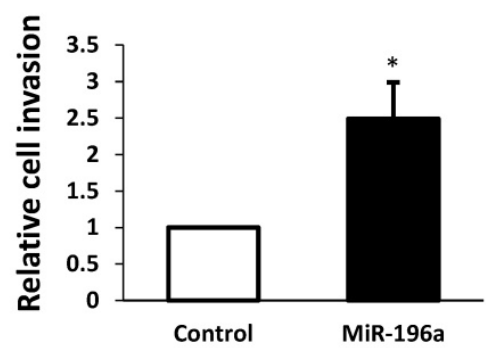

Anti-miR control Anti-miR-196a
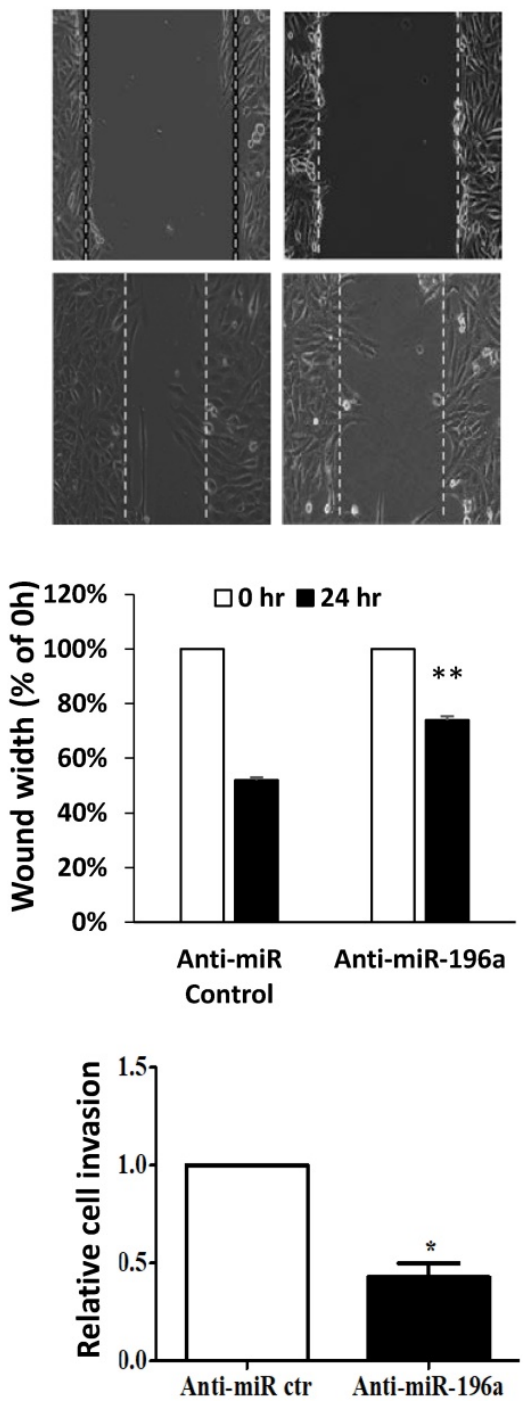

Figure 4. MiR-196a plays an oncogenic role in renal cells in vitro. (A) MiR-196a promotes cell proliferation in renal cells. HEK293T and RCC4 cells were transfected with miR-196a plasmids or anti-miR-196a nucleotides or negative control, followed by cell titer and crystal violet assay. Data is representative of three independent experiments. $* \mathrm{P}<0.05$. $* \mathrm{P}<0.01$. (B) The effect of miR-196a on colony forming ability in HEK293T and RCC4 cells. Untransfected cells and cells transfected with miR-196a plasmids or anti-miR-196a nucleotides or negative control were followed by crystal violet staining and imaging capture. Data is representative of three independent experiments. $* P<0.05$. (C) MiR-196a promotes renal cell migration by wound healing assay. HEK293T and RCC4 cells were transfected with miR-196a plasmids or anti-miR-196a nucleotides or negative control, followed by wound healing assay measured at $0 \mathrm{hr}$ and $24 \mathrm{hr}$. The width of the wound in each well is quantified and presented as average \pm SD. Data is representative for three independent experiments. $* * \mathrm{P}<0.001$. (D) HEK293T and RCC4 cells were transfected with miR-196a plasmids or anti-miR-196a nucleotides or negative control and seeded in the upper chamber of transwell plates. The cell number on the outside surface of this chamber was counted after 48 hours. Duplicates were performed in three independent experiments. ${ }^{*} \mathrm{P}<0.05$.

Table 1. Candidate targets for miR-196a

\begin{tabular}{lllll}
\hline Targeting gens & Target Scan & miRWalk & DIANAmicroT & PicTar \\
\hline Bram1 & 100 & 0.923 & 1.000 & 6.56 \\
HOXA7 & 100 & 0.846 & 1.000 & 3.25 \\
HOXB6 & 91 & - & 0.991 & 3.22 \\
ING5 & 78 & 0.864 & 0.881 & 2.17 \\
SMURF1 & 55 & 0.471 & - & - \\
CDC73 & 62 & 0.515 & - & 2.19 \\
MAP3K1 & 84 & 0.500 & 0.981 & 2.80 \\
DIRC2 & 51 & - & - & -
\end{tabular}

4 microRNA target prediction software (Target Scan, miRWalk, DIANAmicroT and PicTar) were used for molecular target prediction for miR-196a. Besides the ones that have been reported, the others are listed in the table according to their binding score to microRNA.
Moreover, using the above target-predication softwares, the 3'UTR of Bram1 was scanned for predicted miR-196a target sites. The eight nucleotides comprising the seed sequences of miR-196a showed complete complementarity of two target sites in human 3'UTR of Bram1. To confirm that miR-196a directly targets Bram1, we cloned the wild-type and mutant 3'-UTR of Bram1 construct in psicheck2 vector (Supplementary Figure 1). Subsequently, these luciferase 3'-UTR constructs were co-transfected with miR-196a or empty vector plasmids into HEK293T cells. MiR-196a decreased the activity of the luciferase reporter containing the wild-type 3'-UTR of Bram1 
mRNA, while no change for the luciferase reporter containing the mutant 3 '-UTR of Bram1 mRNA (Figure 5B). We further confirmed that miR196a could regulate mRNA and protein expression of Bram1 using qPCR and western blotting in HEK293T cells transfected with miR-196a vectors. Indeed, Bram1 mRNA and protein was downregulated compared with cells transfected with control (Figure 5C,D). This result confirms that miR-196a targets Bram1 by directly targeting its 3 '-UTR.

\section{Bram 1 inhibits renal cell migration and invasion, but not cell growth}

We next determined the effect of Bram1 on renal cell proliferation and migration/invasion. HEK293T cells were transfected with either an EV or Bram1 or shBram1 constructs (Figure 6A, B) Cells transfected with Bram1 did not exhibit significant differences in cell proliferation compared with cells transfected with empty vectors indicating that Bram1 does not affect renal cell proliferation rates (Figure 6C). However, RCC4 cells transfected with Bram1 exhibited significantly less invasion than cells transfected with empty vectors (Figure 6D). Conversely, when HEK293T cells were silenced for Bram1, cell migration significantly increased. Similar results were obtained with a wound healing assay (Figure 6E). This data indicates that overexpression of Bram1 can inhibit migration and invasion of RCC4 cells, while silencing
Bram1 increases HEK293T cell invasion and wound healing.

\section{Bram 1 inhibits cell migration and invasion via MAPK and BMP pathways by binding to EGFR and BMPRIA}

Next, we investigated the mechanism of how Bram1 inhibits cell migration and invasion. Overexpression of Bram1 decreased the expression of p-SMAD1/5/8 in BMP pathway (Figure 7A). SMAD activity was quantified using the luciferaseexpressing vector (Figure 7B). Overexpression of Bram1 in RCC4 cells significantly decreases SMAD luciferase activity, while silencing Bram1 in HEK293T cells results in higher SMAD luciferase activity, confirming that Bram1 can regulate the activation of SMAD. Besides, overexpression of Bram1 decreased the activation of ERK, p-EGFR and p38 MAPK (Figure 7C), while it did not affect p-JNK. Conversely, silencing Bram1 increases the expression level of p-ERK, p-JNK, p-EGFR and p-p38. Furthermore, overexpression of Bram1 decreased the expression of p-Raf (Figure 7D). To further investigate whether pharmacological inhibition of p42/p44 MAPK can affect the Bram1-induced cell migration suppression, the MEK inhibitor, U0126 was used (Figure 7E, F). UO126 further enhanced the Bram1 overexpressioninduced cell migration suppression. These data indicate that Bram1 can inhibit cell migration via MAPK and BMP pathways.
A

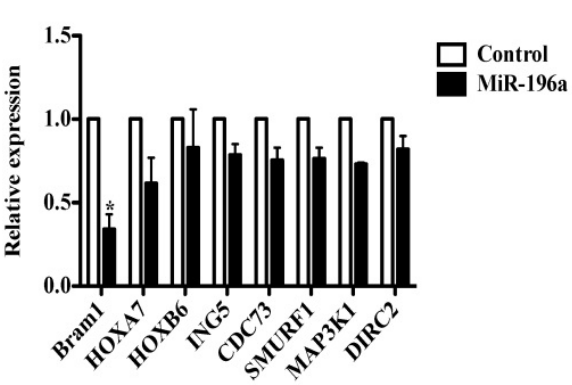

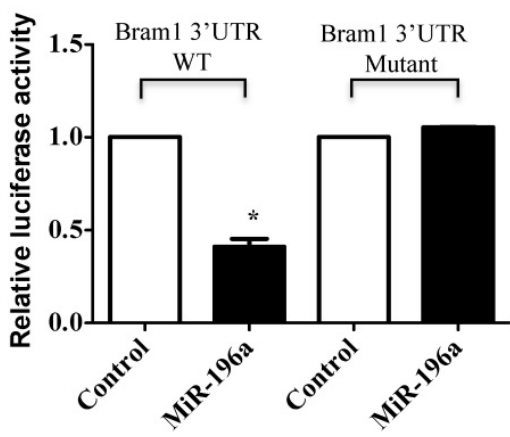

C

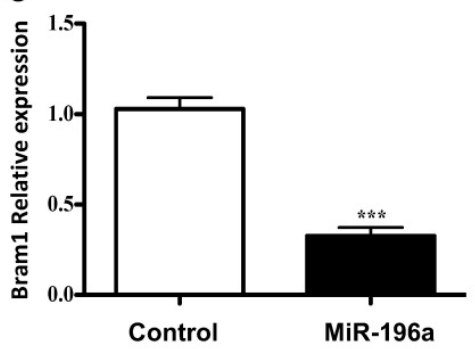

D

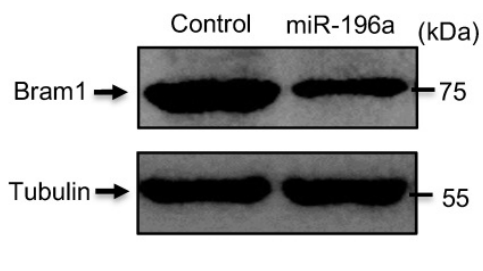

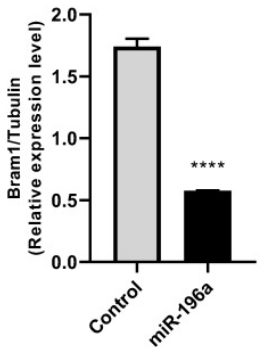

Figure 5. Braml is a direct target of miR-196a. (A) Gene screening for miR-196a candidate targets. HEK293T cells were transfected with miR-196a, and the expression level of indicated genes was quantified by RT-PCR. (B) The luciferase reporter containing wild-type Bram1 3'-UTR or mutant Bram1 3'-UTR was co-transfected into HEK293T cells with miR-196a plasmids and control. Luciferase activity was determined by the dual luciferase assay and normalized to Renilla activity. (C, D) HEK293T cells were transfected with empty vector or miR-196a, mRNA and protein expression were determined using RT-PCR and western blot. ***P<0.001. 
A

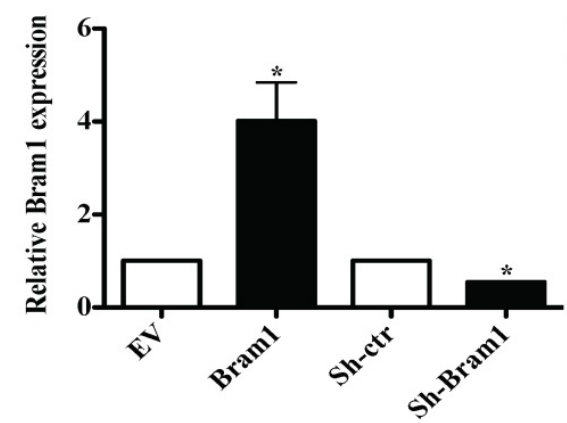

C

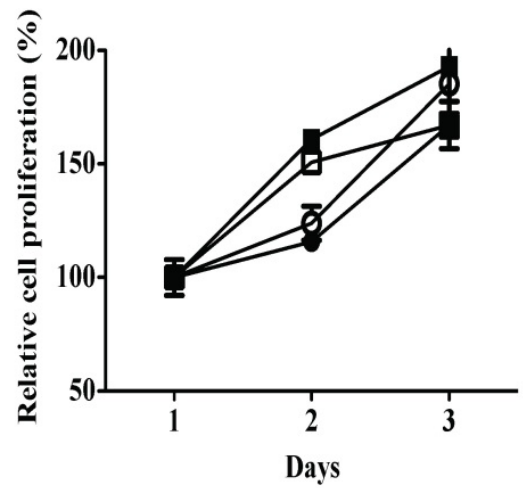

E

E EV
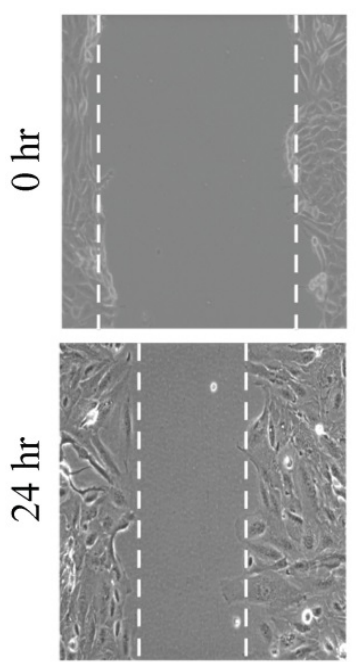

B

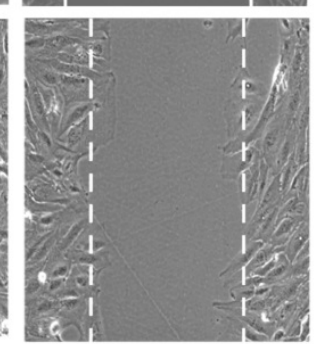

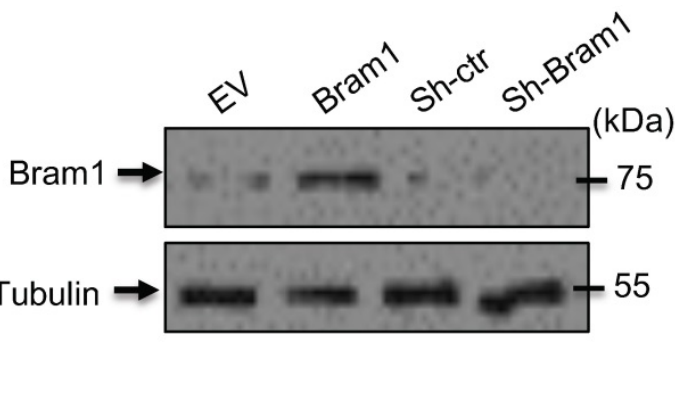

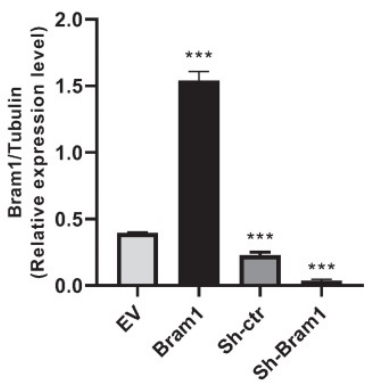

D

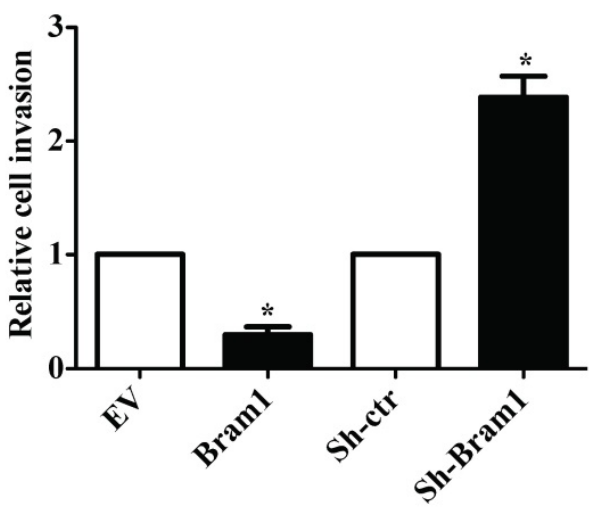

Sh-ctr

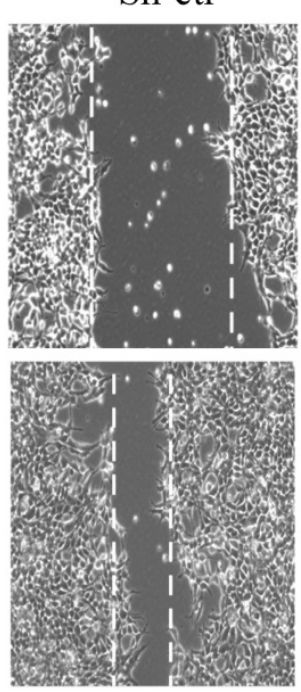

Sh-Bram1

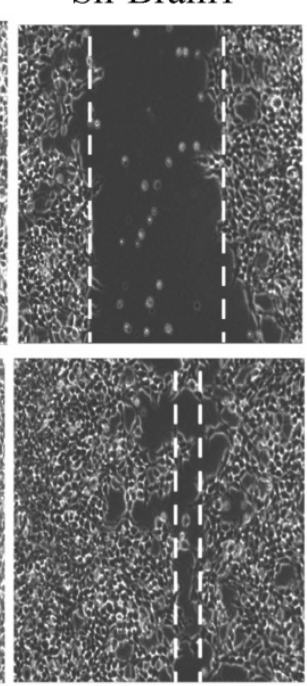

- Bram1
— Sh-ctr
- Sh-Bram1
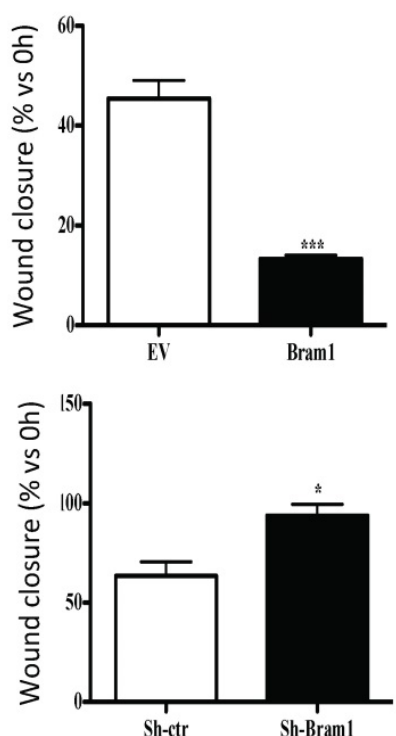

Figure 6. Braml inhibits renal cell migration and invasion, but not cell growth. (A) RCC4 and HEK293T cells were transfected with Braml plasmids or shBraml plasmids and its relative control (EV or sh-ctr), mRNA level of Braml in these cells was detected by RT-PCR. Data is representative of three independent experiments. $* \mathrm{P}<0.05$. (B) RCC4 and HEK293T cells were transfected with Braml plasmids or shBraml plasmids and their relative control (EV or sh-ctr). The protein level of Braml in these cells was detected by western blot. (C) RCC4 and HEK293T cells were transfected with Braml plasmids or shBraml plasmids and its relative control (EV or sh-ctr), followed by cell titer assay. (D) RCC4 and HEK293T cells were transfected with Braml plasmids or shBraml plasmids and its relative control (EV or sh-ctr), followed by transwell assay. Duplicates were performed in three independent experiments. ${ }^{*} \mathrm{P}<0.05$. (E) RCC4 and HEK293T cells were transfected with Braml plasmids or shBraml plasmids and its relative control (EV or sh-ctr), followed by wound healing assay. The width of the wound in each well is quantified and presented in average \pm SD. Data is representative of three independent experiments. $* \mathrm{P}<0.05$. $* * * \mathrm{P}<0.001$.

Bram1 has been reported to bind to BMPR1A, which is the upstream protein of BMP pathway. Our immunoprecipitation data was shown that Bram1 could bind to BMPR1A. Moreover, Bram1 has been reported mainly to interact with membrane proteins, so we hypothesized that Bram1 can possibly interact with EGFR to inhibit the MAPK pathway. Immunoprecipitation experiments demonstrate that Bram1 physically interacts with both BMPR1A and EGFR (Figure 7G). 
A $\quad$ EV $\quad$ Braml Sh-ctr Sh-Braml (kDa)
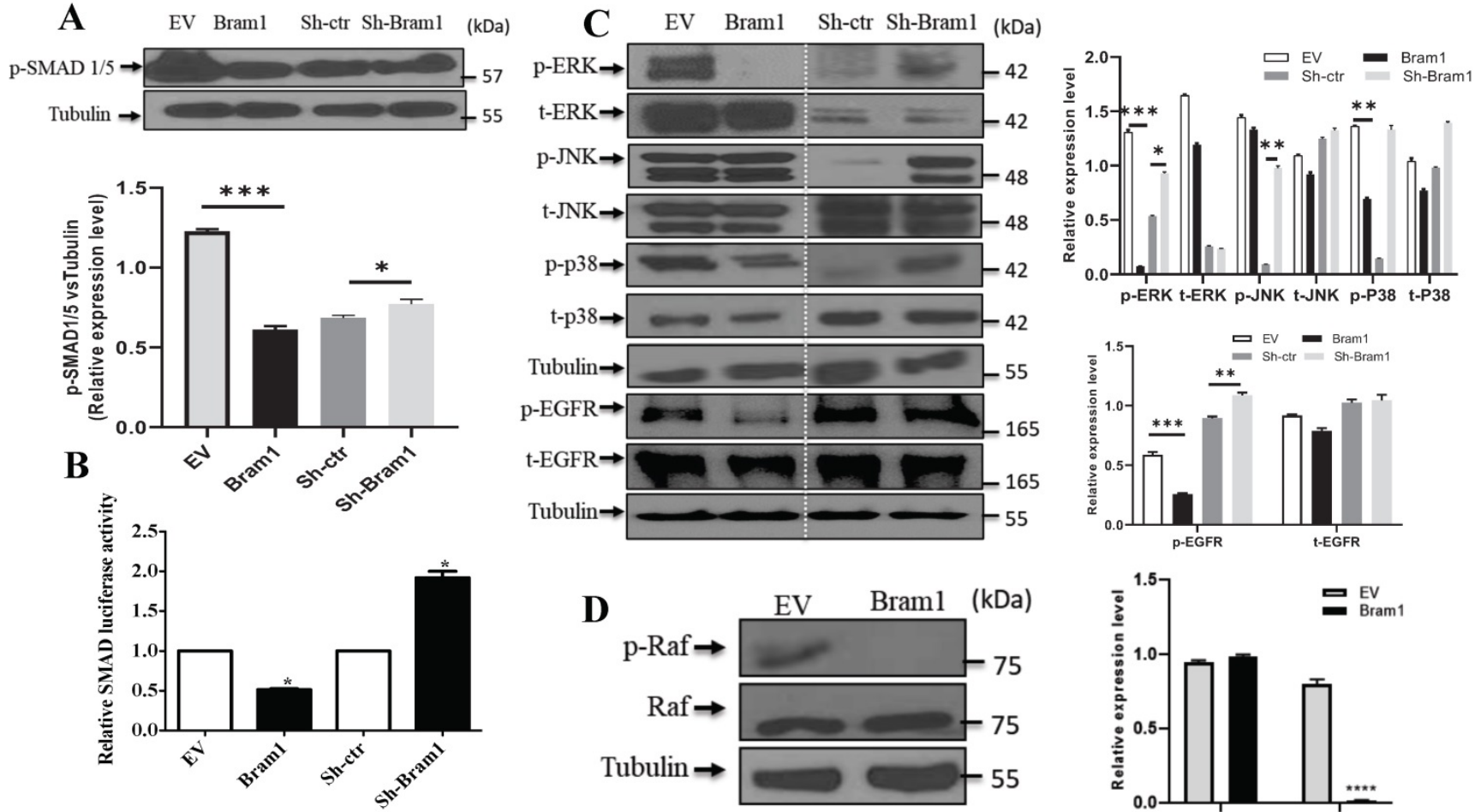

$\mathbf{E}$
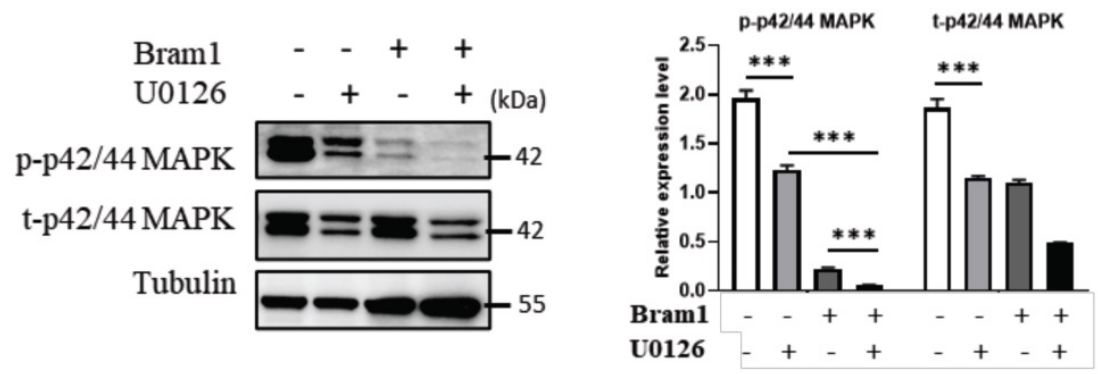

F
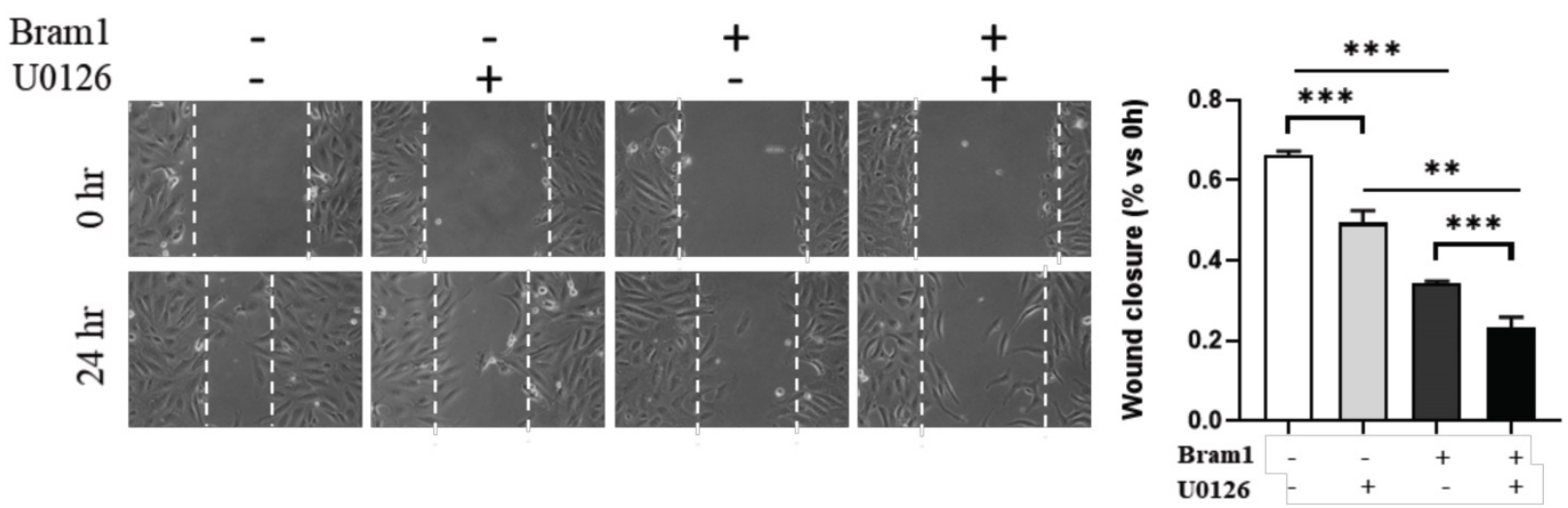

G

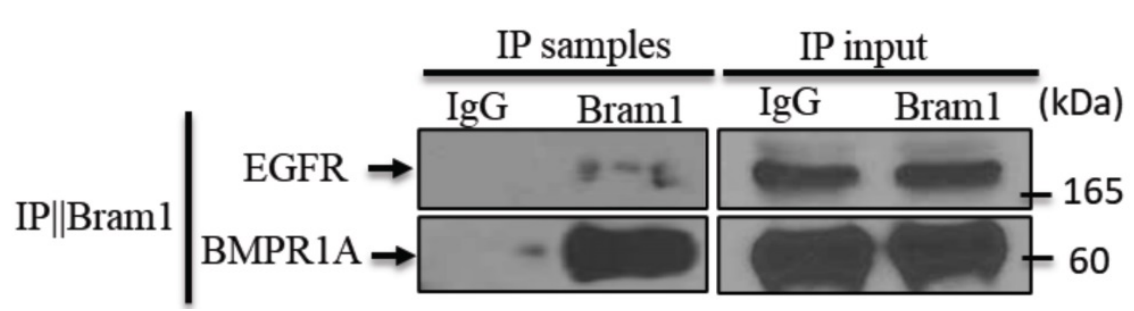


H

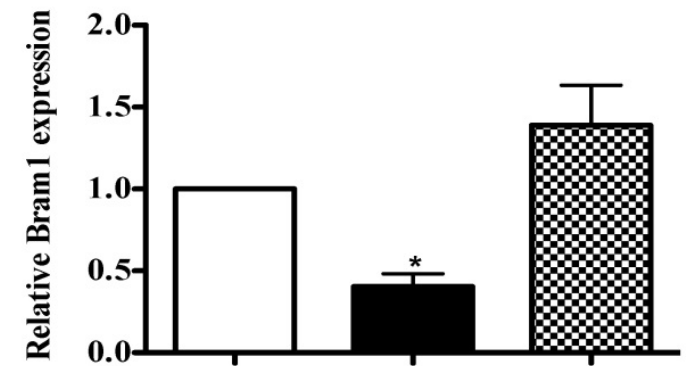

Control

MiR-196a

Bram 1

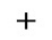

$-$
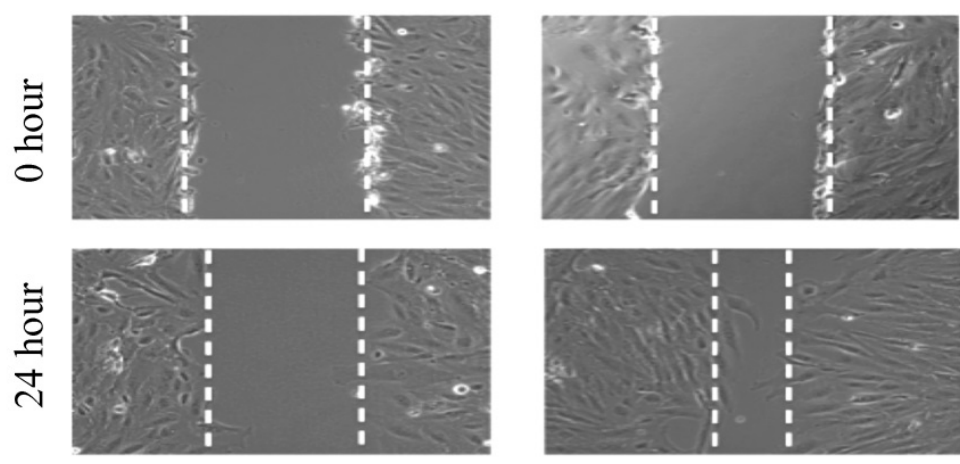

Control

I

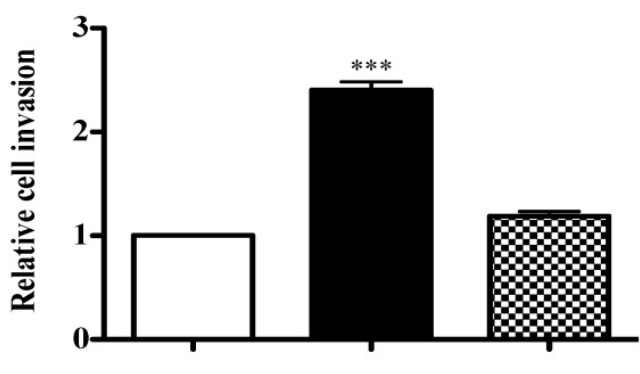

Control

MiR-196a

Bram 1

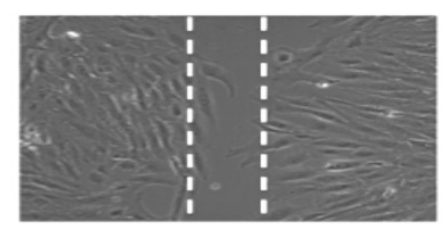

MiR-196a
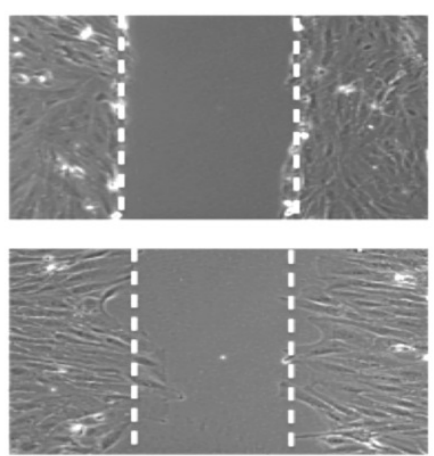

MiR-196a \& Bram1

Figure 7. Bram 1 inhibits cell migration and invasion via MAPK and BMP pathways by binding to EGFR and BMPR1A. (A) HEK293T cells were transfected with Braml or shBraml and the expression level of phosphorylated SMAD1/5/8 and tubulin was examined by Western Blot assay. Data is representative of three independent experiments. (B) HEK293T cells were co-transfected with SMAD luciferase plasmids and Bram1 or shBram 1 plasmids, and the lysate was used for luciferase assay. *P<0.05. (C, D) cells were transfected with Braml or shBraml, and the expression level of indicated proteins was examined by Western Blot assay. (E) Protein level of phosphate p42/44 and total p42/44 in empty vector (-) and Braml overexpression (+) RCC4 cells with or without U0126 treatment (10 $\mu$ M, 4 hours). (F) Wound healing assay analysis the effect of MAPK inhibitor and Braml overexpression on cell migration (10 $\mu$ M U0126 treatment for 4 hours). (G) The physical interaction between Bram1 and BMPR IA or EGFR was investigated by immunoprecipitation experiments. HEK293T cells were transfected with flag-Braml, and treated with $50 \mu M$ BMP4, 48 hr post-transfection the lysates were collected and incubated with normal beads as a negative control or flag-beads. (H) RCC4 cells were co-transfected with miR-196a and Braml plasmids, the expression of Braml was detected by RT-PCR. *P<0.05. (I) RCC4 cells were co-transfected with miR-196a and Braml plasmids and seeded in the upper chamber of transwell plates. Duplicates were performed in three independent experiments. $* * * \mathrm{P}<0.001$. (J) RCC4 cells were co-transfected with miR-196a and Bram1 plasmids, followed by wound healing assay measured at $0 \mathrm{hr}$ and $24 \mathrm{hr}$. Data is representative of three independent experiments.

\section{MiR-196a-induced cell migration and invasion can be rescued by Bram 1}

To investigate whether Bram1 was involved in the increase in renal cancer cell migration induced by miR-196a, we performed co-transfection experiments. We found that co-transfection of Bram1 and miR-196a reversed the decreased expression of Bram1 protein induced by miR-196a (Figure 7H). Moreover, transwell assays (Figure 7I) and wound healing assays (Figure 7J) indicated that the co-transfection could partially rescue miR-196a-promoted migration in HEK293T cells. These data indicate that miR-196a could promote cell migration through the downregulation of Bram1 expression.

\section{Discussion}

It has been reported that the expression of miR-196a in cancer is cancer-type specific $[14,15,20$, 31]. Like many other miRNAs, miR196a is significantly reduced in metastatic vs primary renal tumors [9]. The SNP (rs11614913) of miR-196a-2 is associated with RCC susceptibility and survival, serving as a biomarker for RCC occurrence and prognosis [5]. Our results with renal cancer cells demonstrated that miR-196a is higher in all three cancer cells compared to normal human embryonic kidney HEK293T cells. This may be because all the cell lines used in our study (786-O, RCC4 and Caki1) are primary renal cancer cells and it is possible that miR-196a is increased in primary tumors and lost during the metastatic process of epithelial to mesenchymal transition (EMT). Although the underlying mechanism of the miRNA expression loss remains unclear, other studies have previously shown that the extracellular matrix crosslinking enzyme tissue transglutaminase-2 (TG2) only emerges in metastatic cells undergoing induction and reversion of epithelial-mesenchymal transition [41]. In addition, spleen tyrosine kinase (SYK), TGF- $\beta$ and P-bodies are 
also involved epithelial-mesenchymal plasticity and metastasis through autophagy in cancer cells [42, 43]. Interestingly, epithelial to mesenchymal plasticity also enhanced fibronectin accumulation in paracrine and endocrine signaling, which regulates metastasis in breast cancer cells [44-46]. This 'double face paradox' also exists in the expression of some other proteins, such as TGF $\beta$. In the early stages of cancer, TGF $\beta$ exhibits tumor suppressive functions and inhibits epithelial cell cycle progression and promotes apoptosis. However, in the later stages of cancer, TGF- $\beta 1$ is linked with increased tumor progression, higher cell motility, cancer invasiveness, and metastasis. It is also involved in the modification of the tumor microenvironment and promotion of EMT [47].

This hypothesis of overexpression of miR-196a during tumorigenesis and loss during metastasis can also be observed in breast cancer cells where MCF7 and T47D are seen to express higher levels of miR-196a compared to the more metastatic and invasive breast cancer cells MDA-MB-231, MDA-MB-435 and MDA-MB-468 cells. This seems to suggest that miR-196a is an oncogenic miR which can promote tumor growth, yet its loss in metastatic cells may indicate that it can also have negative roles in EMT, invasion or extravasation.

Molecular targets for miR-196a were discovered by microRNA target prediction software. Among these candidates, Bram1 was chosen for further study as it was the highest hit. Bram1 is a relatively novel gene, and this is the first study on Bram1 and miRNA regulation. A negative correlation was indeed observed in the expression level of Bram1 and miR-196a in renal cancer cells, and expression of miR-196a reduced Bram1 mRNA expression and protein levels. The 3'UTR luciferase assay showed miR-196a directly targets the $3^{\prime}$-UTR of Bram1, and Bram1 is involved in miR-196a-induced cell migration. Similar experiments have been done in other published studies, for example, Sox4, which is one target of miR-212, was shown to be involved in the miR-212 inhibitory tumor progression; p27Kip1, which is one target of miR-429, was observed to partially rescue the proliferation-promoting effect of miR-429 in IA8 cells $[48,49]$.

Bram1 was shown to be highly expressed in renal cancer cells. Thus, the targeting of Bram1 by miR-196a might provide a mechanism on the modulation of Bram1 expression in renal cancer cells. Bram1, or otherwise known as ZMYND11, was identified in 1998 as an alternative spliced variant of BS69, which has been identified as a transcription suppressor gene [33]. Bram1 mainly exists in the cytoplasm while BS69 exists in nucleus [50].
Therefore, Bram1 may have different functions from BS69. Through its MYND domain in C-terminal, Bram1 has been reported to bind with some membrane proteins directly and regulate the relative pathway, such as BMPR1A [33], where it associates with BMPR1A in zebrafish and mammalian cells and blocks the BMP pathway. It can also inhibit NFKB activation by binding to LMP1 [36] and LT $\beta R$ [37]. In C. elegans, BRA-1, a homolog of BRAM1, binds to DAF-1 and negatively regulates and DAF7 pathways, which are the homolog of TGF- $\beta$ pathways [35]. Bram1, as the target of miR-196 has been demonstrated in glioblastoma multiforme which revealed the important role of miR-196 and Bram1in cancer suppression [51] in cell growth and cell invasion. The underlying mechanisms and the downstream pathways remain unknown, however, although a previous study indicated that Bram1 suppressive effect on c-myb, myc and histone H3.3 might be considered [52-54].

In our study, Bram1 significantly inhibited cell migration in renal cancer cells, while it did not affect cell proliferation. To further investigate how Bram1 regulates migration, the main pathways involved in cancer migration were studied. Bram1 negatively regulated SMAD and ERK activation. The relationship between Bram1 and BMPR1A, which blocks SMAD pathway, was confirmed in this study by immunoprecipitation. This has previously been reported in different cells $[33,34]$. Moreover, the effect of inhibition of phosphorylation of various Smads on metastasis of RCC has been studied previously. Fibronectin silencing decreased cell growth and migration via suppression of the expression of cyclin D1, vimentin, and Smad3 phosphorylation in CAKI-1 and 786-O cells [55]. Similarly, overexpression of CD82, also known as KAI-1, inhibited migration and invasion by suppressing phosphorylation of Smad2 and Smad3 and TGF- $\beta 1 /$ Smad/MMP pathway in CAKI-1 cells.) These results are consistent with our finding in BRAM1, which suggest that CD82 and BRAM1 may inhibit RCC cells metastasis via inhibition of phosphorylation of various Smads [56].

As described above, cytosolic Bram1 has been shown to associate with membrane proteins. Therefore, we hypothesized that Bram1 might associate with the EGF receptor to inhibit MAPK activation as evidenced by immunoprecipitation assay, which has not been previously reported. Our studies confirmed that not only in GBM, but also for the other cancer cell lines, such as kidney cancers, the function of Bram1 as well as the role of miR-196 in cell progression, growth, migration, and invasion are functionally conserved. More importantly, we hereby demonstrate the potential underlying mechanism of 
miR-196 regulation of BRAM1 via SMAD and MAPK by directly binding to BMPR1A and EGFR, which contribute to the biological function mentioned above.

We have shown that the expression of miR-196a in primary clear cell renal cancer cells is up regulated, which suggests miR-196a might be a potential biomarker for primary renal cancer cells. Further, miR-196a plays an oncogenic role in renal cells, promoting cell proliferation and cell migration and invasion. Our study indicates that miR-196a may play a key role in RCC metastasis processes. The upregulated expression of miR-196a provides an important link to identifying suitable therapeutic targets (BRAM1) and diagnostic biomarkers for RCC. However, using a miRNA as a tumor marker often lacks specificity. The expression of miR-21 was significantly upregulated in RCC compared with healthy kidneys [58]. However, other studies reported that RCC exhibited significantly lower expression levels of miR-21, -141 and -200b than normal tissues [59]. These findings suggested that the combination of many miRNAs markers and other types of tumor markers and the targeting genes will significantly improve the accuracy of diagnosis [57]. In terms of prognosis, more studies have showed that aberrant miRNA expression is associated with overall survival, disease grade and stage, recurrence, and metastasis [60]. Since metastasis is common in RCC, miRNA196 expression and the negative correlation with BRAM1 expression indicates that miR-196a is associated with poor prognosis and may pave the way to clinical use of miRNAs as prognostic markers for metastasis. Due to the significant roles of miRNAs in the diagnosis and prognosis of cancer, increasing efforts are dedicated to the development of miRNA-based therapies. Either restoring functions of tumorsuppressive miRNAs or inhibiting oncogenic miRNAs could benefit cancer therapy. For example, silencing of miR-210 expression decreased the viability of ACHN and CAKI-2 cells and reduced the migratory and invasive potential of $\mathrm{ACHN}$ metastatic RCC cells [61]. Hence, our results suggest that downregulation of miR-196 may suppress cell migration and act in a tumor-suppressive way in RCC. Moreover, miRNA-based therapies may also be used together with other therapeutic strategies, such as MAPK/ERK kinase inhibitors, in pre-clinical studies to enhance therapy strategies further.

\section{Conclusions}

MiR-196a plays critical regulatory roles in renal cancer and the role of miR-196a in cancer is tissueand cell type-specific. In the present work, miR-196a significantly induces renal cancer cell proliferation, migration and invasion by directly targets 3 'UTR of
Bram1 both in vitro and in vivo. Further investigation revealed that the underlining mechanism of Bram1 suppression is via the inhibition of Smad1/5/8 phosphorylation and MAPK pathway by directly binding to BMPR1A and EGFR. Thus, our results provide a new clue of the potential role of miR-196a in tumor metastasis and tumor suppression in renal cancer cells.

\section{Abbreviations}

BMP: Bone morphogenesis protein; BMPR1A: Bone morphogenesis protein receptor 1A; Bram1: Bone morphogenesis protein receptor associated molecule 1; EGF: Epidermal Growth Factor; EMT: Epithelial to mesenchymal transition; ERK: Extracellular signal-regulated kinases; GDAC: Global Disaster Alert and Coordination System; HOX: Homeobox miRNAs; miR: MicroRNAs; MAPK: Mitogen-activated protein kinases; MYND: MyeloidNervy-DEAF-1; RCC: Renal cell carcinoma; TGF- $\beta$ : Transforming growth factor-beta; LT $\beta R$ : Lymphotoxin beta receptor; UTR: Untranslated region.

\section{Supplementary Material}

Supplementary figure $\mathrm{S} 1$.

http://www.ijbs.com/v17p4254s1.pdf

\section{Acknowledgements}

The authors would like to thank Dr Yu-San Chang from Chang-Gung University for kindly providing the pCMV-Bram1 and psupe-shBram1 and the negative controls.

\section{Funding}

The work was supported by a grant from the National Kidney Foundation (R185-000-214-592) to LHKL and a grant from the National Medical Research Council of Singapore (Grant No: CBRG14may066) to LHKL and APK, and a grant from the National Research Foundation-Singapore-HUJ Alliance for Research and Enterprise initiative which supports JCZ. The work was supported by a grant from the Singapore Ministry of Education Tier 2 (MOE-T2EP30120-0016) to APK. APK and TZT are also supported by the National Medical Research Council of Singapore and the Singapore Ministry of Education under its Research Centres of Excellence initiative to Cancer Science Institute of Singapore, National University of Singapore.

\section{Author Contributions}

JC, YY generated the data presented in this study. MKS performed the in vivo mice work and edited the manuscript. DA, JC assisted in editing the 
manuscript. TZT performed renal cancer patient dataset analysis and generated figures from these analyses. GS and APK provided reagents and analysis to the data presented in this study. LHKL conceived the idea for this study and directed the entire study. LHKL and APK finalized this manuscript.

\section{Competing Interests}

The authors have declared that no competing interest exists.

\section{References}

1. Bartel DP. MicroRNAs: genomics, biogenesis, mechanism, and function. Cell. 2004; 116: 281-97.

2. Lee RC, Feinbaum RL, Ambros V. The C. elegans heterochronic gene lin-4 encodes small RNAs with antisense complementarity to lin-14. Cell. 1993; 75: 843-54.

3. Croce CM. Causes and consequences of microRNA dysregulation in cancer. Nature reviews Genetics. 2009; 10: 704-14.

4. Lopez-Beltran A, Scarpelli M, Montironi R, Kirkali Z. 2004 WHO classification of the renal tumors of the adults. European urology. 2006; 49: 798-805.

5. Du M, Lu D, Wang $\mathrm{O}, \mathrm{Chu} \mathrm{H}$, Tong N, Pan X, et al. Genetic variations in microRNAs and the risk and survival of renal cell cancer. Carcinogenesis. 2014; 35: 1629-35.

6. White NM, Bao TT, Grigull J, Youssef YM, Girgis A, Diamandis M, et al. miRNA profiling for clear cell renal cell carcinoma: biomarker discovery and identification of potential controls and consequences of miRNA dysregulation. The Journal of urology. 2011; 186: 1077-83.

7. Slaby O, Jancovicova J, Lakomy R, Svoboda M, Poprach A, Fabian P, et al. Expression of miRNA-106b in conventional renal cell carcinoma is a potential marker for prediction of early metastasis after nephrectomy. Journal of experimental \& clinical cancer research : CR. 2010; 29: 90

8. Heinzelmann J, Henning B, Sanjmyatav J, Posorski N, Steiner T, Wunderlich $\mathrm{H}$, et al. Specific miRNA signatures are associated with metastasis and poor prognosis in clear cell renal cell carcinoma. World journal of urology. 2011; 29: 367-73.

9. White NM, Khella HW, Grigull J, Adzovic S, Youssef YM, Honey RJ, et al. miRNA profiling in metastatic renal cell carcinoma reveals a tumour-suppressor effect for miR-215. British journal of cancer. 2011; 105: 1741-9.

10. Zhang L, Xul B, Chen S, Lu K, Liu C, Wang Y, et al. The complex roles of microRNAs in the metastasis of renal cell carcinoma. Journal of nanoscience and nanotechnology. 2013; 13: 3195-203.

11. Kong X, Du Y, Wang G, Gao J, Gong Y, Li L, et al. Detection of differentially expressed microRNAs in serum of pancreatic ductal adenocarcinoma patients: miR-196a could be a potential marker for poor prognosis. Digestive diseases and sciences. 2011; 56: 602-9.

12. Hoffman AE, Zheng T, Yi C, Leaderer D, Weidhaas J, Slack F, et al. microRNA miR-196a-2 and breast cancer: a genetic and epigenetic association study and functional analysis. Cancer research. 2009; 69: 5970-7.

13. Kim YJ, Bae SW, Yu SS, Bae YC, Jung JS. miR-196a regulates proliferation and osteogenic differentiation in mesenchymal stem cells derived from human adipose tissue. Journal of bone and mineral research : the official journal of the American Society for Bone and Mineral Research. 2009; 24: 816-25.

14. Schimanski CC, Frerichs K, Rahman F, Berger M, Lang H, Galle PR, et al. High miR-196a levels promote the oncogenic phenotype of colorectal cancer cells. World journal of gastroenterology : WJG. 2009; 15: 2089-96.

15. Liu XH, Lu KH, Wang KM, Sun M, Zhang EB, Yang JS, et al. MicroRNA-196a promotes non-small cell lung cancer cell proliferation and invasion through targeting HOXA5. BMC cancer. 2012; 12: 348

16. Tsai KW, Liao YL, Wu CW, Hu LY, Li SC, Chan WC, et al. Aberrant expression of miR-196a in gastric cancers and correlation with recurrence. Genes, chromosomes \& cancer. 2012; 51: 394-401.

17. Park YG, Lee KH, Lee JK, Lee KT, Choi DW, Choi SH, et al. [MicroRNA expression pattern in intraductal papillary mucinous neoplasm]. The Korean journal of gastroenterology = Taehan Sohwagi Hakhoe chi. 2011; 58: 190-200.

18. Braig S, Mueller DW, Rothhammer T, Bosserhoff AK. MicroRNA miR-196a is a central regulator of HOX-B7 and BMP4 expression in malignant melanoma. Cellular and molecular life sciences : CMLS. 2010; 67: 3535-48.

19. Dou LP, Li YH, Wang LL, Yu L. [HOXA9 is direct target of miR-196a]. Xi bao yu fen zi mian yi xue za zhi = Chinese journal of cellular and molecular immunology. 2011; 27: 166-9.

20. Sun M, Liu XH, Li JH, Yang JS, Zhang EB, Yin DD, et al. MiR-196a is upregulated in gastric cancer and promotes cell proliferation by downregulating p27(kip1). Molecular cancer therapeutics. 2012; 11: 842-52.

21. Luthra R, Singh RR, Luthra MG, Li YX, Hannah C, Romans AM, et al. MicroRNA-196a targets annexin A1: a microRNA-mediated mechanism of annexin A1 downregulation in cancers. Oncogene. 2008; 27: 6667-78.
22. Coskun E, von der Heide EK, Schlee C, Kuhnl A, Gokbuget N, Hoelzer D, et al. The role of microRNA-196a and microRNA-196b as ERG regulators in acute myeloid leukemia and acute T-lymphoblastic leukemia. Leukemia research. 2011; 35: 208-13.

23. Tripurani SK, Lee KB, Wee G, Smith GW, Yao J. MicroRNA-196a regulates bovine newborn ovary homeobox gene (NOBOX) expression during early embryogenesis. BMC developmental biology. 2011; 11: 25.

24. Hou T, Ou J, Zhao X, Huang X, Huang Y, Zhang Y. MicroRNA-196a promotes cervical cancer proliferation through the regulation of FOXO1 and p27Kip1. British journal of cancer. 2014; 110: 1260-8.

25. Zhang J, Zheng F, Yu G, Yin Y, Lu Q. miR-196a targets netrin 4 and regulates cell proliferation and migration of cervical cancer cells. Biochemical and biophysical research communications. 2013; 440: 582-8.

26. Wang K, Li J, Guo H, Xu X, Xiong G, Guan X, et al. MiR-196a binding-site SNP regulates RAP1A expression contributing to esophageal squamous cell carcinoma risk and metastasis. Carcinogenesis. 2012; 33: 2147-54.

27. Yang G, Han D, Chen X, Zhang D, Wang L, Shi C, et al. MiR-196a exerts its oncogenic effect in glioblastoma multiforme by inhibition of IkappaBalpha both in vitro and in vivo. Neuro-oncology. 2014; 16: 652-61.

28. Tsai MM, Wang CS, Tsai CY, Chen CY, Chi HC, Tseng YH, et al. MicroRNA-196a/-196b promote cell metastasis via negative regulation of radixin in human gastric cancer. Cancer letters. 2014; 351: 222-31.

29. Huang F, Tang J, Zhuang X, Zhuang Y, Cheng W, Chen W, et al. MiR-196a promotes pancreatic cancer progression by targeting nuclear factor kappa-B-inhibitor alpha. PloS one. 2014; 9: e87897.

30. Miyazaki $Y$, Adachi H, Katsuno M, Minamiyama M, Jiang YM, Huang Z, et al. Viral delivery of miR-196a ameliorates the SBMA phenotype via the silencing of CELF2. Nature medicine. 2012; 18: 1136-41.

31. Lu YC, Chang JT, Liao CT, Kang CJ, Huang SF, Chen IH, et al. OncomiR-196 promotes an invasive phenotype in oral cancer through the NME4-JNK-TIMP1-MMP signaling pathway. Molecular cancer. 2014; 13: 218

32. Mueller DW, Bosserhoff AK. MicroRNA miR-196a controls melanoma-associated genes by regulating HOX-C8 expression. International journal of cancer Journal international du cancer. 2011; 129: 1064-74.

33. Kurozumi K, Nishita M, Yamaguchi K, Fujita T, Ueno N, Shibuya H. BRAM1, a BMP receptor-associated molecule involved in BMP signalling. Genes to cells : devoted to molecular \& cellular mechanisms. 1998; 3: 257-64.

34. Wu KM, Huang CJ, Hwang SP, Chang YS. Molecular cloning, expression and characterization of the zebrafish bram1 gene, a BMP receptor-associated molecule. Journal of biomedical science. 2006; 13: 345-55.

35. Morita K, Shimizu M, Shibuya H, Ueno N. A DAF-1-binding protein BRA-1 is a negative regulator of DAF-7 TGF-beta signaling. Proceedings of the National Academy of Sciences of the United States of America. 2001; 98: 6284-8.

36. Chung PJ, Chang YS, Liang CL, Meng CL. Negative regulation of Epstein-Barr virus latent membrane protein 1-mediated functions by the bone morphogenetic protein receptor IA-binding protein, BRAM1. The Journal of biological chemistry. 2002; 277: 39850-7.

37. Liu HP, Chung PJ, Liang CL, Chang YS. The MYND domain-containing protein BRAM1 inhibits lymphotoxin beta receptor-mediated signaling through affecting receptor oligomerization. Cellular signalling. 2011; 23: 80-8.

38. Geissmann Q. OpenCFU, a New Free and Open-Source Software to Count Cell Colonies and Other Circular Objects. PloS one. 2013; 8: e54072.

39. Ekimler S, Sahin K. Computational Methods for MicroRNA Target Prediction. Genes. 2014; 5: 671-83.

40. Á. Bartha, B. Győrffy, TNMplot.com: A Web Tool for the Comparison of Gene Expression in Normal, Tumor and Metastatic Tissues Int. J. Mol. Sci. 2021; 22(5):2622.

41. Shinde A, Paez JS, Libring S, Hopkins K, Solorio L, Wendt MK. Transglutaminase-2 facilitates extracellular vesicle-mediated establishment of the metastatic niche. Oncogenesis. 2020; 9: 16.

42. Hardy SD, Shinde A, Wang W-H, Wendt MK, Geahlen RL. Regulation of epithelial-mesenchymal transition and metastasis by TGF- $\beta$, P-bodies, and autophagy. Oncotarget. 2017; 8: 103302-14.

43. Shinde A, Hardy SD, Kim D, Akhand SS, Jolly MK, Wang WH, et al. Spleen Tyrosine Kinase-Mediated Autophagy Is Required for Epithelial-Mesenchymal Plasticity and Metastasis in Breast Cancer. Cancer research. 2019; 79: 1831-43

44. Libring S, Shinde A, Chanda MK, Nuru M, George H, Saleh AM, et al. The Dynamic Relationship of Breast Cancer Cells and Fibroblasts in Fibronectin Accumulation at Primary and Metastatic Tumor Sites. Cancers (Basel). 2020; 12: 1270 .

45. Shinde A, Libring S, Alpsoy A, Abdullah A, Schaber JA, Solorio L, et al. Autocrine Fibronectin Inhibits Breast Cancer Metastasis. Molecular cancer research: MCR. 2018; 16: 1579-89.

46. Shinde A, Wilmanski $\mathrm{T}$, Chen $\mathrm{H}$, Teegarden D, Wendt MK. Pyruvate carboxylase supports the pulmonary tropism of metastatic breast cancer. Breast Cancer Research. 2018; 20: 1-12.

47. Zarzynska JM. Two FACes of TGF-beta1 in breast cancer. Mediators of inflammation. 2014; 2014: 141747.

48. Luo XJ, Tang DG, Gao TL, Zhang YL, Wang M, Quan ZX, et al. MicroRNA-212 Inhibits Osteosarcoma Cells Proliferation and Invasion by Down-Regulation of Sox4. Cellular physiology and biochemistry : international journal of experimental cellular physiology, biochemistry, and pharmacology. 2014; 34: 2180-8. 
49. Ouyang Y, Gao P, Zhu B, Chen X, Lin F, Wang X, et al. Downregulation of microRNA-429 inhibits cell proliferation by targeting p27Kip1 in human prostate cancer cells. Molecular medicine reports. 2015; 11: 1435-41.

50. Masselink H, Bernards R. The adenovirus E1A binding protein BS69 is a corepressor of transcription through recruitment of N-CoR. Oncogene. 2000; 19: $1538-46$.

51. Yang J-p, Yang J-k, Li C, Cui Z-q, Liu H-j, Sun X-f, et al. Downregulation of ZMYND11 induced by miR-196a-5p promotes the progression and growth of GBM. Biochemical and biophysical research communications. 2017; 494: 674-80.

52. Guan Y, Mizoguchi M, Yoshimoto K, Hata N, Shono T, Suzuki SO, et al. MiRNA-196 is upregulated in glioblastoma but not in anaplastic astrocytoma and has prognostic significance. Clinical Cancer Research. 2010; 16: 4289-97.

53. Swartling FJ. Myc proteins in brain tumor development and maintenance. Upsala journal of medical sciences. 2012; 117: 122-31.

54. Shindo H, Tani E, Matsumuto T, Hashimoto T, Furuyama J. Stabilization of c-myc protein in human glioma cells. Acta neuropathologica. 1993; 86: 345-52.

55. Ou Y-C, Li J-R, Wang J-D, Chang C-Y, Wu C-C, Chen W-Y, et al. Fibronectin Promotes Cell Growth and Migration in Human Renal Cell Carcinoma Cells. International Journal of Molecular Sciences. 2019; 20: 2792.

56. Zhu J, Liang C, Hua Y, Miao C, Zhang J, Xu A, et al. The metastasis suppressor CD82/KAI1 regulates cell migration and invasion via inhibiting TGF- $\beta$ 1/Smad signaling in renal cell carcinoma. Oncotarget. 2017; 8: 51559-68.

57. Li M, Wang Y, Song Y, Bu R, Yin B, Fei X, et al. MicroRNAs in renal cell carcinoma: A systematic review of clinical implications (Review). Oncol Rep. 2015; 33: 1571-8

58. Faragalla H, Youssef YM, Scorilas A, Khalil B, White NM, Mejia-Guerrero S, et al. The clinical utility of miR-21 as a diagnostic and prognostic marker for renal cell carcinoma. The Journal of Molecular Diagnostics. 2012; 14: 385-92.

59. Silva-Santos R, Costa-Pinheiro P, Luis A, Antunes L, Lobo F, Oliveira J, et al. MicroRNA profile: a promising ancillary tool for accurate renal cell tumour diagnosis. British journal of cancer. 2013; 109: 2646-53.

60. Liang B, Zhao J, Wang X. A three-microRNA signature as a diagnostic and prognostic marker in clear cell renal cancer: An In Silico analysis. PloS one. 2017; 12: e0180660-e.

61. Redova M, Poprach A, Besse A, Iliev R, Nekvindova J, Lakomy R, et al. MiR-210 expression in tumor tissue and in vitro effects of its silencing in renal cell carcinoma. Tumor Biology. 2013; 34: 481-91. 